\title{
Consumo y manipulación de plantas por parte de los grupos humanos que habitaron las sierras de Córdoba durante el Holoceno tardío (2707 - 383 años AP). Un aporte desde los microrrestos vegetales contenidos en tártaro dental humano
}

\author{
Aldana Tavarone \\ (iD) https://orcid.org/0000-0001-5153-6938 \\ Instituto de Antropología de Córdoba (IDACOR), Facultad de Filosofía y Humanidades, Universidad Nacional de \\ Córdoba (UNC) y Consejo Nacional de Investigaciones Científicas y Técnicas (CONICET). Av. Hipólito Yrigoyen 174 \\ (CP X5000JHO), Córdoba, Argentina. E-mail: aldyt@hotmail.com

\section{M. de los Milagros Colobig} \\ (iD) https://orcid.org/0000-0001-5153-6938 \\ Laboratorio de Arqueología, Centro de Investigación Científica y de Transferencia Tecnológica a la Producción (CICyTTP), \\ Consejo Nacional de Investigaciones Científicas y Técnicas (CONICET) y Universidad Autónoma de Entre Ríos (UADER). \\ España 149 (CP E3105BWA), Diamante, Entre Ríos, Argentina. E-mail: milagroscolobig@gmail.com

\section{Mariana Fabra} \\ (iD) https://orcid.org/0000-0001-5153-6938 \\ Instituto de Antropología de Córdoba (IDACOR), Facultad de Filosofía y Humanidades, Universidad Nacional de \\ Córdoba (UNC) y Consejo Nacional de Investigaciones Científicas y Técnicas (CONICET). Av. Hipólito Yrigoyen 174 \\ (CP X5000JHO), Córdoba, Argentina. E-mail: marianafabra@gmail.com
}

Recibido: 24 de marzo de 2020 Aceptado: 11 de junio de 2020

\begin{abstract}
Resumen
Investigaciones arqueológicas y arqueobotánicas en la región serrana de la provincia de Córdoba han dado cuenta de la manipulación de una amplia diversidad de especies vegetales desde al menos 2000 años AP, combinando recolección y caza con cultivo a pequeña escala. Sin embargo, las diferencias entre las plantas seleccionadas en los distintos valles así como la cronología de la incorporación de plantas cultivadas aún sigue siendo tema de debate. En este contexto, el presente trabajo contribuye a esta problemática a partir del estudio de microrrestos vegetales contenidos en el cálculo dental de 25 individuos adultos procedentes de la región serrana de Córdoba $(2707 \pm 61-383 \pm 58$ ${ }^{14} \mathrm{C}$ años AP). Se realizó un recuento de los distintos tipos vegetales hallados considerando dos momentos, que representarían cambios en las estrategias de subsistencia (previo y posterior a 1200 años AP), y la procedencia regional (valles de Punilla, Traslasierra y Calamuchita). Los resultados sugieren el consumo y/o la manipulación de Geoffroea decorticans y Prosopis sp. y por primera vez, de Trithrinax campestris a lo largo de todo el Holoceno tardío. A su vez, revelaron la incorporación hacia 1200 años AP de Zea mays (Poaceae), seguida de Cucurbita sp., Phaseolus sp. y Solanum sp.
\end{abstract}




\title{
Consumption and manipulation of plants by the inhabitants of the Córdoba mountain ranges during the Late Holocene (2707 - 383 years BP). A contribution from vegetal micro-remains contained in human dental calculus
}

\begin{abstract}
Archaeological and archaeobotanical investigations in the mountain ranges of Córdoba province, have shown the manipulation of a wide diversity of plant species since at least 2000 years BP, combining harvesting and hunting with small-scale cultivation. However, the differences between the plants selected in the different valleys, as well as the chronology of cultivated plant incorporation, is still a matter of debate. In this context, we contribute to this issue through the study of plant micro-remains contained in the dental calculus of 25 adult individuals from the mountain ranges of Córdoba (2707 $\pm 61-383 \pm 5814 \mathrm{C}$ years BP). The count of the different plant morphotypes identified was made considering two moments that represent changes in subsistence strategies (before and after 1200 years BP), and their regional provenance (Punilla, Traslasierra, and Calamuchita valleys). The results suggest the consumption and/or manipulation of Geoffroea decorticans and Prosopis sp. and, for the first time, of Trithrinax campestris throughout the Late Holocene. Furthermore, they revealed the incorporation of Zea mays (Poaceae), followed by Cucurbita sp., Phaseolus sp., and Solanum sp. towards 1200 BP.
\end{abstract}

KEYWORDS: Silicophytolits; Starch grains; Human dental calculus; Archaeobotany; Prehispanic populations.

\section{Introducción}

El estudio de los microrrestos vegetales (fitolitos, granos de almidón, diatomeas, polen) contenidos en el tártaro dental humano permite abordar cuestiones vinculadas al tipo de alimentos ingeridos y/o manipulados con el aparato masticatorio, su importancia relativa, cambios y continuidades a lo largo del tiempo, las diferentes técnicas de procesado y cocción de los alimentos, así como evaluar el efecto que pueden haber tenido procesos tales como el desarrollo de técnicas agrícolas, la sedentarización o el nucleamiento social en el manejo de distintos tipos de recursos vegetales a lo largo del tiempo (Babot, 2003; Korstanje y Babot, 2007; Medina, Pastor y Berberián, 2014).

Tradicionalmente los estudios sobre la dieta y manipulación de plantas por parte de las poblaciones que habitaron la región serrana de la provincia de Córdoba otorgaron un gran valor a los documentos coloniales de los siglos XVI y XVII, asociando el desarrollo de las prácticas agrícolas con innovaciones tecnológicas y organizativas, como así también la sedentarización en poblados permanentes (De Aparicio, 1936; Berberián, 1999; Canals Frau, 1953).

Las investigaciones arqueológicas y bioarqueológicas indican que las poblaciones asentadas en las diferentes regiones del actual territorio de Córdoba habrían desarrollado distintas adaptaciones que resultaron exitosas a lo largo del tiempo (Laguens, 1999; Laguens y Bonnin, 2009), complementando la caza y recolección con la horticultura (Fabra y González, 2015). Los estudios arqueobotánicos han abordado estas problemáticas desde una perspectiva diferente e innovadora para el área de estudio, evidenciando la presencia de recursos vegetales silvestres y cultivados desde comienzos del Holoceno tardío (Medina et al., 2014; Tavarone, Colobig y Fabra, 2019).

En particular desde la arqueobotánica, se pudo inferir el manejo de una amplia variedad de especies vegetales tanto silvestres como cultivadas (López, 2017; López, Medina y 
Rivero, 2015; Medina, Pastor y Recalde, 2016; Pastor, López y Rivero, 2012-2014; Recalde y López, 2017). La cronología de estos hallazgos en la región serrana ubica el desarrollo de las estrategias basadas en el cultivo de vegetales alrededor de 3000 años AP con las primeras evidencias de Zea mays, mientras que Phaseolus sp. y Cucurbita sp. se habrían incorporado con posterioridad, hacia los $1028 \pm 40$ años AP, aunque es posible que la incorporación de estas especies no haya sido simultánea en toda la región.

Si bien estos estudios han permitido profundizar el conocimiento sobre la manipulación de plantas por parte de las comunidades cazadoras recolectoras y horticultoras que habitaron la región, hasta el momento no se han hecho investigaciones que pongan en valor los microrrestos vegetales contenidos en tártaro dental. En este trabajo, nos proponemos aproximarnos a la problemática de las prácticas de consumo, así como del manejo de las plantas, ya sea para alimentación o como parte de prácticas culturales, desde el estudio de los microrrestos vegetales (silicofitolitos y almidones) contenidos en el tártaro dental de individuos hallados en distintos sitios arqueológicos de la región serrana de la provincia de Córdoba, sobre los que se cuenta con información radiocarbónica precisa, ubicándolos en el Holoceno tardío.

\section{Área de estudio}

Se seleccionaron individuos provenientes de tres valles de la región serrana de la provincia de Córdoba -Punilla, Traslasierra y Calamuchita- (Figura 1). Desde el punto de vista fitogeográfico, los mismos corresponden al denominado Distrito Chaqueño Serrano (ubicado entre 500 - 1.300 m s.n.m.) incluido en la Provincia Chaqueña (Cabrera, 1976; Luti et al., 1979). Aquí encontramos sectores de llanuras con ligeras depresiones o cauces de ríos y en su parte occidental serranías de poca elevación. Las precipitaciones son escasas, principalmente estivales y oscilan entre $500 \mathrm{~mm}$ en la zona occidental y $1200 \mathrm{~mm}$ en la zona oriental; la temperatura puede alcanzar medias entre los 10 y 12 grados y un período de heladas con una duración de hasta 10 meses (Pastor y López, 2010). La zona correspondiente a los encadenamientos del cordón occidental, valles, bolsones y piedemontes ubicados entre los 300 y 900 m s.n.m., presentan suelos pobres y condiciones climáticas más áridas (Recalde y López, 2017). A su vez, la cobertura vegetal varía con la latitud, la altitud, el suelo y los disturbios (Cabido, Carranza, Acosta y Páez, 1991) siendo predominante el bosque xerófilo caducifolio, alternando con estepas de gramíneas duras (Giorgis, Cabido y Cingolani, 2011); también podemos encontrar palmares, sabanas y estepas halófilas, entre otros (Cabrera, 1976).

Las comunidades vegetales principales son los bosques de horco quebracho (Schinopsis haenkeana), mientras que en los faldeos septentrionales también encontramos el quebracho blanco (Aspidosperma quebracho-blanco) y el mistol (Ziziphus mistol). En los faldeos del sur, abundan las especies de molle de beber (Lithraea molleoides), coco (Zanthoxylum coco) y Palma Caranday (Trithrinax campestris). En la zona del matorral serrano tenemos representantes de churqui (Acacia caven) y romerillo (Heterothalamus alienus) (Oyarzabal et al., 2018). En las laderas y piedemontes con afloramientos rocosos, entre los $1.300-1.700 \mathrm{msnm}$, encontramos especies como el tala (Celtis chichape), molle (Schinus areira), tintitaco (Prosopis torquata), sombra de toro (Jodina rhombifolia), aguaribay (Schinus areira), piquillín (Condalia buxifolia y C. montana) y el espinillo (Acacia visco) (Cabido y Zak, 1999).

La zona de las Sierras Grandes presenta bosques de tabaquillo (Polylepis australis) y por encima del bosque de horco-quebracho, encontramos los pastizales de altura, especialmente representados por los géneros Stipa y Festuca (Cabrera, 1976; Oyarzabal et al., 2018) ocupando los filos de cerros y serranías, constituyendo el último piso de vegetación de las Sierras Pampeanas y Subandinas por encima de 1700 - 2000 m s.n.m 


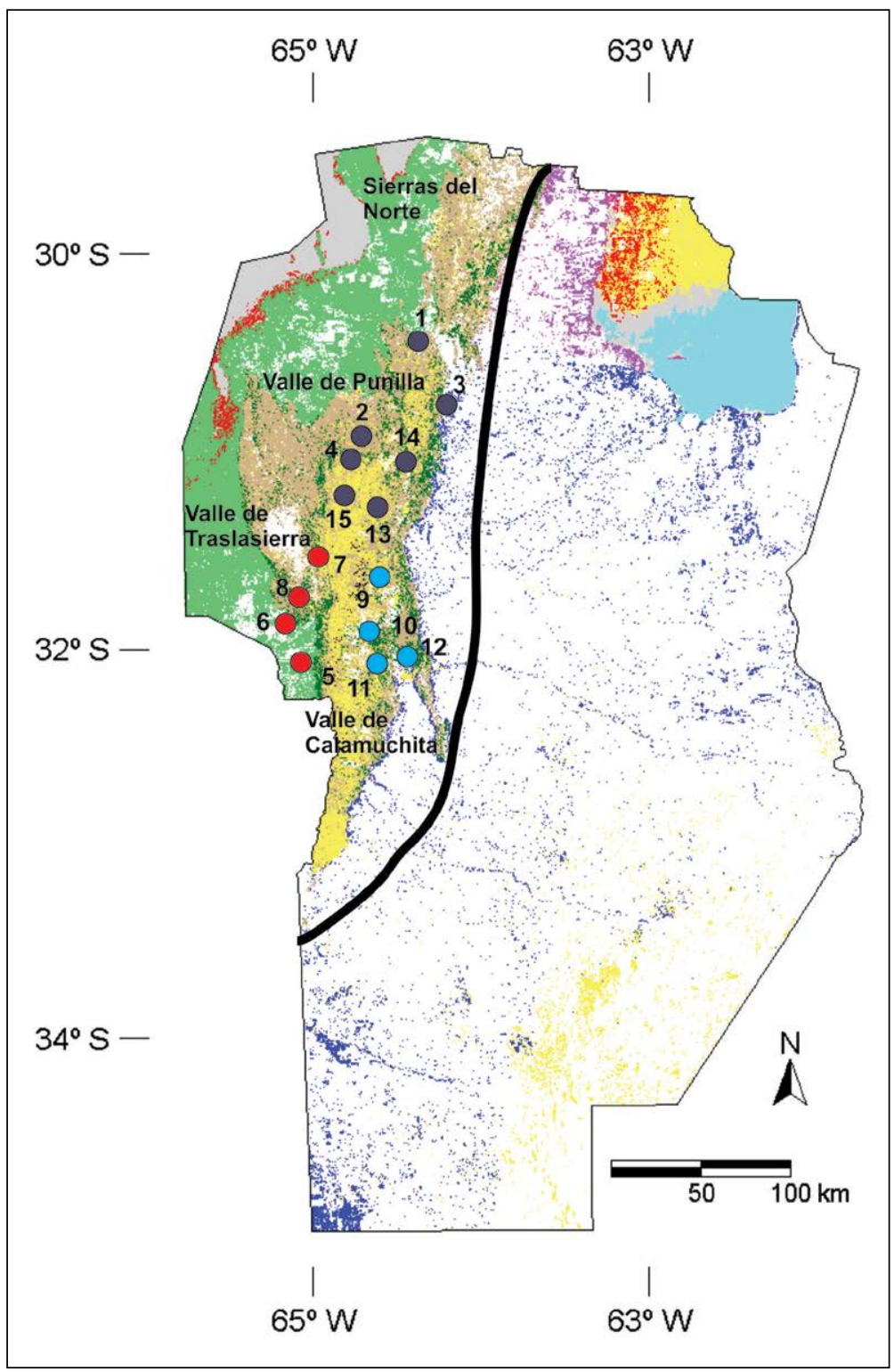

Figura 1. Sitios arqueológicos agrupados por subregiones geográficas de la provincia de Córdoba. Sierras: Valle de Punilla (violeta): 1) Nunsacat; 2) San Esteban; 3) El Vado; 4) Ayampitín; 13) Ecoterra; 14) La Granja; 15) Cuesta Blanca. Valle de Traslasierra (rojo): 5) Loma Bola; 6) Guasmara; 7) Copina; 8) Cañada Larga. Valle de Calamuchita (turquesa): 9) Constantinopla 1215; 10) Loteo 5 - Santa Rosa; 11) Potrero de Garay; 12) Amboy. Mapa modificado de Cabido y colaboradores (2018).

(Cingolani, Renison, Zak y Cabido, 2004; Luti et al., 1979; Pastor y Berberián, 2007). Por último, hacia el Noreste, sobre los 200 m s.n.m., encontramos las Salinas Grandes, cuya vegetación característica son los matorrales de halófitas suculentas (Oyarzabal et al., 2018).

Según las reconstrucciones paleoclimáticas, hacia los 4200 años AP se registra un cambio climático abrupto con temperaturas más elevadas y condiciones más secas que las actuales. Esta etapa se caracterizó por presentar escasas precipitaciones y una alta evaporación, lo que provocó la formación de las Salinas Grandes, la retracción de los paleolagos, erosión en los suelos y una disminución de la oferta de recursos (Piovano, Ariztegui, Córdoba, Cioccale y Sylvestre, 2009). Esta situación se modifica alrededor de los 900-1300 años AP a partir del momento conocido como "Anomalía Climática Medieval" (Riccardi, 1995). 
Desde fines del siglo XIV, se verifica el inicio de un evento conocido como la "Pequeña Edad de Hielo" (Piovano et al., 2009). En general se caracterizó por un importante deterioro climático, con bajas temperaturas y precipitaciones escasas, las cuales se alternaban con lluvias torrenciales en verano. Estos cambios produjeron una reducción de los lagos y la reactivación de la erosión (Cioccale, 1999; Piovano et al., 2009). A lo largo del tiempo, las diferentes comunidades vegetales han acompañado las fluctuaciones climáticas antes mencionadas, modificando sus rangos de distribución debido a la alteración de sus hábitats (Cassiodoro et al., 2013).

\section{La muestra}

Los individuos analizados en este trabajo provienen de 15 sitios arqueológicos distribuidos en tres valles serranos diferentes: valle de Punilla: ocho individuos de siete sitios (2156 $\pm 86-387 \pm 41{ }^{14} \mathrm{C}$ años AP), valle de Traslasierra: siete individuos de cinco sitios (2707 $\pm 61-481 \pm 57{ }^{14} \mathrm{C}$ años AP) y valle de Calamuchita: 10 individuos de cuatro sitios (995 $\pm 161-383 \pm 58{ }^{14} \mathrm{C}$ años AP.), ubicados entre los $30^{\circ}$ y $33^{\circ}$ de latitud Sur y $64^{\circ}$ y $65^{\circ}$ de longitud Oeste (Tabla 1 ).

Para las comparaciones temporales, se ha dividido la muestra en dos momentos que reflejan estrategias de subsistencia diferentes: caza y recolección (previo a 1200 años AP, en adelante, PRE 1200) e incorporación de prácticas hortícolas (posterior a 1200 años AP, en adelante POST 1200).

Para el período PRE $1200\left(2707 \pm 61{ }^{14} \mathrm{C}\right.$ años AP $-1280 \pm 15{ }^{14} \mathrm{C}$ años AP), se recuperaron un total de 39 muestras correspondientes a cuatro individuos adultos: 28 provenientes del valle de Punilla y 11 del valle de Traslasierra, todas de un único individuo (Tabla 1).

Para el período POST 1.200, en el valle de Punilla $\left(1080 \pm 40{ }^{14} \mathrm{C}\right.$ años AP - $387 \pm 41{ }^{14} \mathrm{C}$ años $A P$ ) se recuperó un total de 19 muestras de tártaro dental provenientes de tres individuos. En tanto, para el valle de Traslasierra $\left(954 \pm 85{ }^{14} \mathrm{C}\right.$ años AP - $481 \pm 57{ }^{14} \mathrm{C}$ años $A P$ ) el total de muestras obtenidas fue de 42 pertenecientes a seis individuos adultos. Por último, en el valle de Calamuchita $\left(995 \pm 161{ }^{14} \mathrm{C}\right.$ años AP - $383 \pm 58{ }^{14} \mathrm{C}$ años $A P$ ) el número total de muestras recuperadas fue de 74 , las cuales provienen de 11 individuos adultos (Tabla 1).

\section{Metodología}

Se seleccionaron aquellos individuos que presentaban las siguientes condiciones: a) piezas dentales de donde obtener la muestra y b) que contaran con información contextual y cronológica relativa y absoluta, a fin de situar luego los resultados en un marco temporal y espacial concreto.

Para la extracción del cálculo dental, se siguió la metodología propuesta por Musaubach (2012) y Babot (2007). Durante este paso, y ante la sospecha de un número escaso de microrrestos vegetales en las muestras, no se utilizaron sustancias químicas, sino que el material en crudo fue molido suavemente en un mortero y se colocaron aproximadamente $4 \mathrm{mg}$ de muestra en el portaobjeto; posteriormente, para facilitar la observación bajo el microscopio, se agregaron dos gotas de aceite de cedro (índice de refracción: 1,515) a cada preparación. Para la descripción de la variabilidad fitolítica, se utilizó una clasificación ad-hoc de morfotipos fitolíticos definida en base a los descriptores morfológicos y la clasificación previos, siguiendo a Neumann et al. (2019) y las pautas clasificatorias de Benvenuto, Honaine, Osterrieth 


\begin{tabular}{|c|c|c|c|c|c|c|c|}
\hline$\frac{0}{\bar{N}}$ & Sitio & Individuo & ঙั̊ & $\begin{array}{c}\text { Cronología 14C } \\
\text { años AP }\end{array}$ & $\begin{array}{l}\text { Código de } \\
\text { Laboratorio }\end{array}$ & $\begin{array}{l}\text { Material } \\
\text { fechado }\end{array}$ & $\begin{array}{c}\mathrm{N}^{\circ} \text { de muestras } \\
\text { de tártaro } \\
\text { dental }\end{array}$ \\
\hline \multirow{8}{*}{ 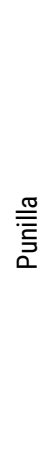 } & Nunsacat $^{1}$ & 1 & $\mathrm{~F}$ & $387 \pm 41$ & --- & --- & 3 \\
\hline & Nunsacat $^{1}$ & 2 & $M$ & $387 \pm 41$ & MTC-13250 & hueso & 4 \\
\hline & Ayampitín ${ }^{2}$ & 1 & M & $600 \pm 20$ & UCI AMS 22287 & diente & 3 \\
\hline & San Esteban ${ }^{3}$ & 1 & $\mathrm{~F}$ & $965 \pm 15$ & UCI AMS 39103 & huesos & 2 \\
\hline & Cuesta Blanca ${ }^{1}$ & 1 & M & $1080 \pm 40$ & MTC-13249 & diente & 7 \\
\hline & La Granja ${ }^{2}$ & 1 & $\mathrm{~F}$ & $1280 \pm 15$ & UCI AMS 22282 & hueso & 1 \\
\hline & Ecoterra $^{4}$ & 1 & M & $1881 \pm 39$ & AA104742 & hueso & 24 \\
\hline & El Vado ${ }^{1}$ & 1 & $\mathrm{~F}$ & $2156 \pm 86$ & MTC-12808 & hueso & 3 \\
\hline \multirow{7}{*}{ 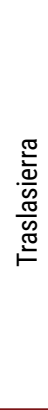 } & Cañada Larga ${ }^{5}$ & 1 & M & $481 \pm 57$ & MTC-14020 & diente & 4 \\
\hline & Copina $^{6}$ & 2 & $M$ & $680 \pm 40$ & MTC-14027 & diente & 8 \\
\hline & Guasmara $^{2}$ & 1 & M & $920 \pm 20$ & -- & --- & 7 \\
\hline & Guasmara $^{2}$ & 2 & M & $920 \pm 20$ & UCI AMS 22281 & diente & 9 \\
\hline & Loma Bola ${ }^{1}$ & $1^{\mathrm{a}}$ & M & $954 \pm 85$ & MTC-12806 & diente & 1 \\
\hline & Loma Bola ${ }^{1}$ & 1B & $\mathrm{F}$ & $954 \pm 85$ & --- & --- & 13 \\
\hline & Copina $^{6}$ & 1 & M & $2707 \pm 61$ & MTC-13248 & diente & 8 \\
\hline \multirow{10}{*}{ 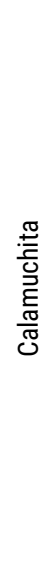 } & Potrero de Garay ${ }^{1}$ & $\mathrm{E} 1 / 58$ & $\mathrm{~F}$ & $383 \pm 58$ & MTC-14025 & diente & 1 \\
\hline & Potrero de Garay ${ }^{1}$ & E9 & M & $420 \pm 41$ & MTC-13254 & hueso & 1 \\
\hline & Loteo 5-Sta Rosa ${ }^{6}$ & 1 & $F$ & $533 \pm 42$ & AA102659 & hueso & 7 \\
\hline & Loteo 5-Sta Rosa ${ }^{6}$ & 2 & $\mathrm{~F}$ & $533 \pm 42$ & --- & --- & 1 \\
\hline & Constantinopla $1215^{6}$ & 1 & M & $619 \pm 43$ & AA102658 & hueso & 13 \\
\hline & Amboy $^{2}$ & 1 & M & $830 \pm 20$ & UCI AMS 22283 & diente & 2 \\
\hline & Potrero de Garay ${ }^{1}$ & $\mathrm{E} 6 / 56$ & M & $881 \pm 150$ & MTC-13215 & diente & 13 \\
\hline & Potrero de Garay ${ }^{6}$ & $\mathrm{E} 4 / 57$ & $\mathrm{~F}$ & $889 \pm 59$ & MTC-14028 & diente & 4 \\
\hline & Potrero de Garay ${ }^{6}$ & $\mathrm{E} 3 / 41$ & $\mathrm{~F}$ & $981 \pm 41$ & MTC-13251 & diente & 20 \\
\hline & Potrero de Garay ${ }^{1}$ & $\mathrm{E} 8 / 53$ & $M$ & $995 \pm 161$ & MTC-13246 & diente & 12 \\
\hline
\end{tabular}

Tabla 1. Número de muestras de tártaro dental recuperadas por individuo. Referencias: F: femenino; M: Masculino; PRE: previo a 1200 años AP. POST: posterior a 1200 años AP; MTC: Universidad de Tokio; UCIAMS: Universidad de Irving; AA: Universidad de Arizona; ' Fabra y Demarchi (2013); ${ }^{2}$ Laguens, Fabra, Dos Santos y Demarchi (2009); ${ }^{3}$ Fabra, Salega y González (2009); ${ }^{4}$ Gonzalez y Fabra (2018); ${ }^{5}$ este trabajo; ${ }^{6}$ Fabra y González (2019).

y Morel (2015); Bertoldi de Pomar (1971, 1975); Korstanje y Babot (2007), Gallego y Distel (2004), Twiss (1992) y Zucol (1999). Estos autores también fueron tomados en cuenta para establecer las asociaciones botánicas de los morfotipos diagnósticos (Colobig, 2014). Las descripciones de los granos de almidón se realizaron siguiendo las pautas y los atributos cualitativos y cuantitativos propuestos por Babot (2003, 2007), Babot, Oliszewski y Grau (2007), Cortella y Pochettino (1994), Heider y López (2016), Korstanje y Babot (2007) y el ICSN (2011). Para el reconocimiento y cuantificación de los elementos se utilizó un microscopio petrográfico Nikon Eclipse E 200 con una cámara digital incorporada. Cada preparación se escaneó sistemáticamente de extremo a extremo, utilizando un aumento total de 400x. Los microrrestos vegetales encontrados fueron fotografiados y referenciados para su posterior conteo e identificación. 


\section{Resultados}

\section{Valle de Punilla}

Se recuperaron microrrestos de plantas silvestres, cuyas afinidades botánicas las refieren principalmente a la familia de las poáceas ( $N$ total $=588 ;$ PRE 1200: $N=428$, POST 1200: $N=160$ ). A su vez, se observaron elementos silíceos de forma circular y color rosado o amarillento, como así también granos de almidón de contorno regular e irregular, con el hilum en posición central, excéntrica o punteada y la cruz de Malta central y excéntrica. Estos atributos según Babot (2003), Giovannetti, Lema, Bartoli y Capparelli (2008) y Korstanje y Babot (2007) pueden ser asociados a los frutos comestibles del género Prosopis (Fabaceae) "algarrobo" ( $\mathrm{N}$ total = 90; PRE 1200: N $=65$, POST: $1200 \mathrm{~N}=25$ ). Sin embargo, los silicofitolitos de este género no poseen características diagnósticas que permitan su identificación específica. Por otro lado, se observaron elementos poliédricos de textura plana e incolora $(N$ total $=21$; PRE 1200: $N=17$, POST 1200: $N=4$ ) que permiten referirlos a la presencia de Geoffroea decorticans (Fabaceae) "chañar", según los criterios propuestos por Korstanje y Babot (2007) y Medina, López y Berberián (2009). Por último, los fitolitos esféricos equinados ( $\mathrm{N}$ total = 5; PRE 1200: $\mathrm{N}=4$, POST 1200: $\mathrm{N}=1$ ) fueron vinculados a la familia de las Arecáceas, particularmente con la especie Trithrinax campestris "Palma Caranday" (Benvenuto et al., 2015) (Tabla 2, Figura 2).

Para el período POST 1200, se observaron siete $(N=7)$ elementos almidonosos de forma irregular y contorno poligonal en las muestras de dos individuos fechados entre $1080 \pm 40$ y $387 \pm 41{ }^{14} \mathrm{C}$ años AP cuyas características morfológicas los refieren taxonómicamente al "maíz" Zea mays (Poaceae) (Pearsall, Chandler-Ezell y ChandlerEzell, 2003; Pearsall, Chandler-Ezell y Zeidler, 2004; Piperno, 2006) y la presencia de tres $(\mathrm{N}=3)$ granos de almidón ovalados similares a los citados para el género Phaseolus sp. "poroto" según lo descripto por Korstanje y Babot (2007), Babot y colaboradores (2007) y Bonomo, Politis y Gianotti García (2011). Finalmente, se contabilizaron 257 elementos silíceos que no pudieron ser asociados a ningún grupo vegetal del cual se tenga actualmente registro (Tabla 2, Figura 2).

\section{Valle de Traslasierra}

Se analizaron un total de siete $(\mathrm{N}=7)$ individuos de los cuales sólo uno corresponde al período PRE 1200 . El mismo $\left(2707 \pm 61{ }^{14} \mathrm{C}\right.$ años $\left.\mathrm{AP}\right)$ reveló la presencia de 72 elementos silíceos, los cuales fueron asociados a gramíneas; también se identificaron 77 morfotipos silíceos y almidonosos afines al género Prosopis sp. "algarrobo" (Babot, 2003) y 11 cuya morfología poliédrica de textura plana e incolora, permitió referirlos al género Geoffroea decorticans "chañar" según Korstanje y Babot (2007) y Medina y colaboradores (2009) (Tabla 3, Figura 3). Es interesante destacar que no se encontró evidencia de plantas cultivadas durante este período.

Para el período POST 1200 se observaron abundantes morfotipos afines a gramíneas $(\mathrm{N}=715)$. Por otro lado, un total de 224 elementos fueron asociados al género Prosopis sp. "algarrobo", mientras que 18 morfotipos silíceos indicaron la presencia de Geoffroea decorticans "chañar" en las muestras de tártaro dental. Además, se registraron cinco silicofitolitos esféricos equinados afines a la especie Trithrinax campestris "Palma Caranday" (Benvenuto et al., 2015) en tres individuos con una antigüedad comprendida entre los $954 \pm 85$ y $481 \pm 57{ }^{14} \mathrm{C}$ años AP. A su vez, se registraron 25 elementos almidonosos en dos individuos con antigüedades de $954 \pm 85{ }^{14} \mathrm{C}$ años AP y $920 \pm 20$ ${ }^{14} \mathrm{C}$ años $\mathrm{AP}$, afines a la especie Zea mays "maíz". Se observaron siete granos de almidón 


\begin{tabular}{|c|c|c|c|c|}
\hline Región & Sitio & $\begin{array}{c}\text { Cronología 14C } \\
\text { años AP }\end{array}$ & Taxón & $\begin{array}{l}N^{\circ} \text { de microrrestos } \\
\text { vegetales }\end{array}$ \\
\hline \multirow{29}{*}{ 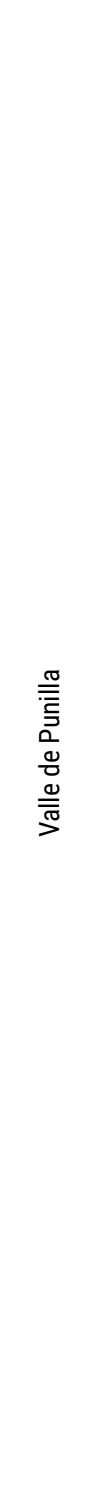 } & \multirow{5}{*}{ Nunsacat } & \multirow{5}{*}{$387 \pm 41$} & Poaceae & 25 \\
\hline & & & Prosopis sp. & 9 \\
\hline & & & Zea mays & 4 \\
\hline & & & Phaseolus sp. & 3 \\
\hline & & & $S / I$ & 24 \\
\hline & \multirow{3}{*}{ Ayampitín } & \multirow{3}{*}{$600 \pm 20$} & Poaceae & 43 \\
\hline & & & Prosopis sp. & 1 \\
\hline & & & $S / I$ & 1 \\
\hline & \multirow{4}{*}{ San Esteban } & \multirow{4}{*}{$965 \pm 15$} & Poaceae & 31 \\
\hline & & & Prosopis sp. & 1 \\
\hline & & & Geoffroea decorticans & 2 \\
\hline & & & $S / I$ & 3 \\
\hline & \multirow{6}{*}{ Cuesta Blanca } & \multirow{6}{*}{$1080 \pm 40$} & Poaceae & 61 \\
\hline & & & Prosopis sp. & 14 \\
\hline & & & Geoffroea decorticans & 2 \\
\hline & & & Trithrinax campestris & 1 \\
\hline & & & Zea mays & 3 \\
\hline & & & S/I & 7 \\
\hline & \multirow{2}{*}{ La Granja } & \multirow{2}{*}{$1280 \pm 15$} & Poaceae & 17 \\
\hline & & & Geoffroea decorticans & 1 \\
\hline & \multirow{5}{*}{ Ecoterra } & \multirow{5}{*}{$1881 \pm 39$} & Poaceae & 398 \\
\hline & & & Prosopis sp. & 60 \\
\hline & & & Geoffroea decorticans & 15 \\
\hline & & & Trithrinax campestris & 4 \\
\hline & & & $S / I$ & 209 \\
\hline & \multirow{4}{*}{ El Vado } & \multirow{4}{*}{$2156 \pm 86$} & Poaceae & 13 \\
\hline & & & Prosopis sp. & 5 \\
\hline & & & Geoffroea decorticans & 1 \\
\hline & & & $S / I$ & 13 \\
\hline
\end{tabular}

Tabla 2. Número total de microrrestos vegetales recuperados de las muestras analizadas para el valle de Punilla.

los cuales fueron vinculados al género Phaseolus sp. "poroto" y un silicofitolito cuyas características morfológicas permitieron asociarlo a la familia de las Cucurbitáceas, en un individuo con una antigüedad de $954 \pm 85{ }^{14} \mathrm{C}$ años AP. Por último, se logró la identificación de tres $(\mathrm{N}=3)$ granos almidonosos afines probablemente a la especie Solanum tuberosum "papa", según lo propuesto por Korstanje y Babot (2007). Los mismos presentaron una antigüedad entre $920 \pm 20$ y $680 \pm 40{ }^{14} \mathrm{C}$ años AP. Finalmente, se documentó el hallazgo de un total de 186 silicofitolitos que aún no han logrado ser identificados (Tabla 3, Figura 3).

\section{Valle de Calamuchita}

Los nueve individuos recuperados corresponden al período POST 1200 (995 \pm 161 ${ }^{14} \mathrm{C}$ años AP $-383 \pm 58{ }^{14} \mathrm{C}$ años AP). Se detectaron un total de 867 elementos que 


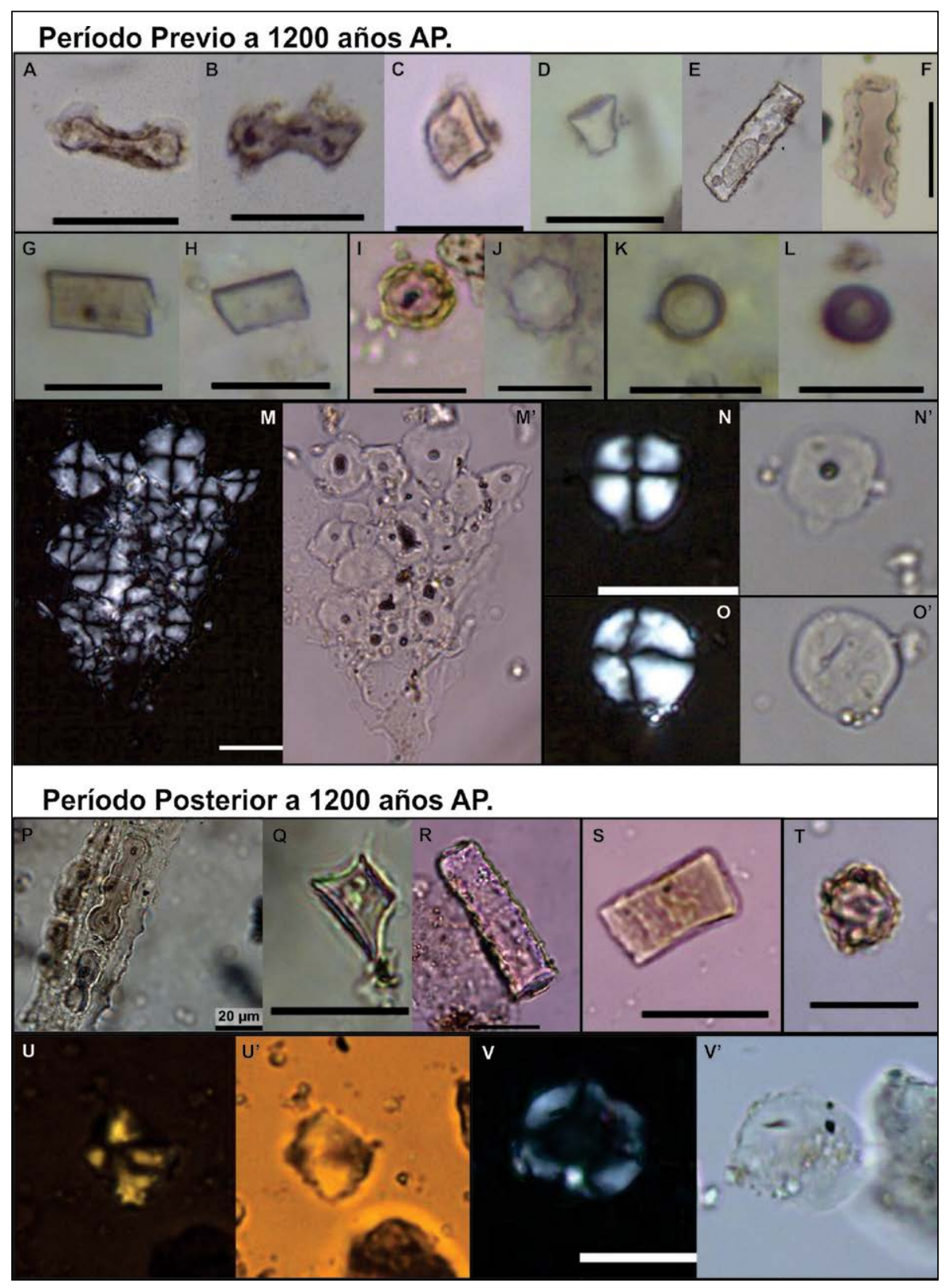

Figura 2. Microrrestos vegetales hallados en el valle de Punilla. PRE 1200 años AP: A-B) silicofitolitos bilobados; $C$-D) en forma de cono truncado; E-F) silicofitolitos prismáticos; G-H) Morfotipos poliédricos; I-J) silicofitolitos esféricos equinados; $K-L$ ) formas circulares; $\left.M-M^{\prime}, N-N^{\prime}, 0-0^{\prime}\right)$ granos de almidón circulares. POST 1200 años AP: $P$ ) fitolitos bilobados articulados; $Q)$ cono truncado; $R$ ) prismático; S) poliédrico; $T$ ) silicofitolito esférico equinado; U-U') grano de almidón poligonal; V-V') Grano de almidón oval. Escala: 20 $\mu m$.

fueron referidos a la familia de las poáceas, 196 morfotipos silíceos y almidonosos se asociaron con la presencia del género Prosopis sp., 31 elementos silíceos a la especie Geoffroea decorticans "chañar" y cuatro a la especie Trithrinax campestris "palma caranday". Con respecto a las plantas cultivadas, se observaron en seis individuos seis granos de almidón de contorno poligonal y un silicofitolito asociado a las partes comestibles de la especie Zea mays "maíz" (wavy-top rondel) como así también un silicofitolito afín a sus hojas (en forma de cruz), con antigüedades comprendidas entre los $981 \pm 41$ y $420 \pm 41{ }^{14} \mathrm{C}$ años AP. Por último, 260 de los elementos hallados no pudieron ser asignados a ningún grupo vegetal hasta el momento (Tabla 4, Figura 4). 


\begin{tabular}{|c|c|c|c|c|}
\hline Región & Sitio & $\begin{array}{c}\text { Cronologia 14C } \\
\text { años AP. }\end{array}$ & Taxón & $\begin{array}{l}\mathbf{N}^{\circ} \text { de microrrestos } \\
\text { vegetales }\end{array}$ \\
\hline \multirow{5}{*}{$\begin{array}{l}\frac{\pi}{2} \\
\frac{0}{9} \\
\frac{0}{0} \\
\frac{\pi}{6} \\
\frac{0}{0} \\
\frac{0}{\overline{0}}\end{array}$} & Cañada Larga & $481 \pm 57$ & $\begin{array}{c}\text { Poaceae } \\
\text { Prosopis sp. } \\
\text { Geoffroea decorticans } \\
\text { Trithrinax campestris } \\
\text { S/l }\end{array}$ & $\begin{array}{l}38 \\
4 \\
1 \\
1 \\
2\end{array}$ \\
\hline & Copina & $680 \pm 40$ & $\begin{array}{c}\text { Poaceae } \\
\text { Prosopis sp. } \\
\text { Geoffroea decorticans } \\
\text { Trithrinax campestris } \\
\text { Solanum sp. } \\
\text { S/l }\end{array}$ & $\begin{array}{c}144 \\
27 \\
10 \\
3 \\
1 \\
84\end{array}$ \\
\hline & Guasmara & $920 \pm 20$ & $\begin{array}{c}\text { Poaceae } \\
\text { Prosopis sp. } \\
\text { Geoffroea decorticans } \\
\text { Zea mays } \\
\text { Solanum sp. }\end{array}$ & $\begin{array}{c}353 \\
51 \\
1 \\
15 \\
2 \\
\end{array}$ \\
\hline & Loma Bola & $954 \pm 85$ & $\begin{array}{c}\text { Poaceae } \\
\text { Prosopis sp. } \\
\text { Geoffroea decorticans } \\
\text { Trithrinax campestris } \\
\text { Zea mays } \\
\text { Phaseolus sp. } \\
\text { Cucurbita sp. } \\
\text { S/I }\end{array}$ & $\begin{array}{c}180 \\
142 \\
6 \\
1 \\
10 \\
7 \\
1 \\
76\end{array}$ \\
\hline & Copina & $2707 \pm 61$ & $\begin{array}{c}\text { Poaceae } \\
\text { Prosopis sp. } \\
\text { Geoffroea decorticans } \\
\text { S/I }\end{array}$ & $\begin{array}{l}72 \\
77 \\
11 \\
24\end{array}$ \\
\hline
\end{tabular}

Tabla 3. Número total de microrrestos vegetales recuperados de la muestra analizada para el valle de Traslasierra.

En los tres valles y a lo largo de ambos períodos temporales fue posible observar que un total de 123 granos de almidón mostraron evidencia de daño consistente con la exposición al calor -tanto hervido como tostado-, la manipulación y el procesamiento de alimentos, como lo demuestran las alteraciones tales como grietas, distorsión, superficie quebrada, una cruz de extinción expandida e hinchazón general (Babot, 2003; Henry y Piperno, 2008; Henry, Hudson y Piperno, 2009). A su vez, se observaron 19 silicofitolitos rotos, principalmente de morfología bilobada y rectangular.

En relación con la presencia de plantas silvestres, se evidencia que a lo largo de todo el Holoceno tardío y en los tres valles analizados, los morfotipos silíceos afines a gramíneas fueron los más abundantes, seguido por los elementos relacionados al algarrobo (Prosopis sp.) y, en menor medida, aquellos afines a chañar (Geoffroea decorticans) y a la palma caranday (Trithrinax campestris). Destacamos que los tres taxones continúan estando representados en ambos períodos cronológicos en proporciones similares, lo cual remarca la importancia de estos recursos para las 


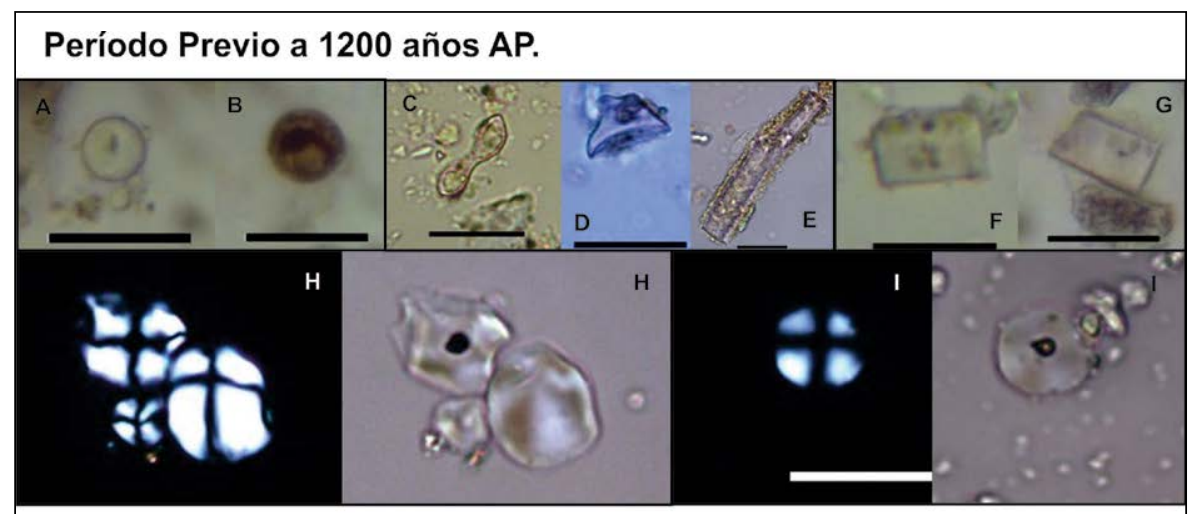

\section{Período Posterior a 1200 años AP.}

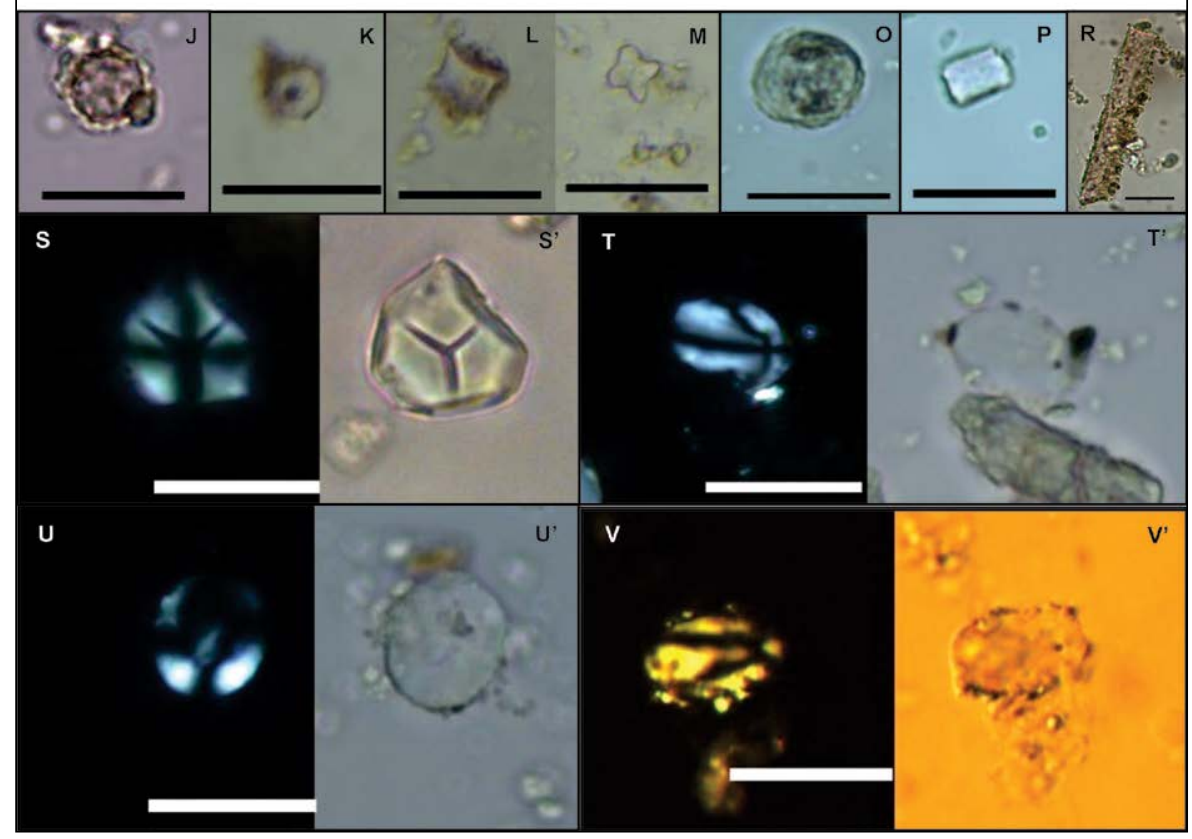

Figura 3. Valle de Traslasierra. PRE 1200 años AP: A-B) morfotipos circulares; C) silicofitolito bilobado; $D$ ) en forma de cono truncado; E) silicofitolito prismático; $F-G$ ) morfotipos poliédricos; $H$ - $\left.H^{\prime}, I-I^{\prime}\right)$ granos de almidón circulares y poligonales. POST 1200 años AP: J) silicofitolito esférico equinado; $K$ ) elemento circular; L) Morfotipo wavy-top rondel; $M$ ) silicofitolito en forma de cruz; 0 ) silicofitolito globular facetado; $P$ ) elemento poliédrico; $R$ ) silicofitolito prismático; $S$-S') grano de almidón poligonal; T-T', U-U'. V-V') granos de almidón ovalados. Escala: $20 \mu m$.

poblaciones humanas que habitaron estos ambientes. Con respecto a las plantas cultivadas, se observa una primera incorporación de maíz (Zea mays) en el sitio Cuesta Blanca $\left(1080 \pm 40{ }^{14} \mathrm{C}\right.$ años AP) y luego de poroto (Phaseolus sp.), zapallo o calabaza (Cucurbita sp.) en el sitio Loma Bola ( $954 \pm 85{ }^{14} \mathrm{C}$ años AP) y papa (Solanum tuberosum) en los sitios Guasmara $\left(920 \pm 20{ }^{14} \mathrm{C}\right.$ años AP) y Copina $\left(680 \pm 40{ }^{14} \mathrm{C}\right.$ años AP).

Finalmente, no se registraron diferencias con respecto a los tipos de microrrestos vegetales encontrados entre las distintas caras de las piezas dentales muestreadas (mesial versus distal - bucal / labial vs. lingual / palatal) (Musaubach, 2012).

\section{Discusión}

La información obtenida en este trabajo aporta evidencia directa sobre el consumo y manipulación de plantas, tanto de origen silvestre como cultivado, y contribuye a 


\begin{tabular}{|c|c|c|c|c|}
\hline Región & Sitio & $\begin{array}{c}\text { Cronología 14C } \\
\text { años AP. }\end{array}$ & Taxón & $\begin{array}{c}\mathrm{N}^{\circ} \text { de microrrestos } \\
\text { vegetales }\end{array}$ \\
\hline \multirow{41}{*}{ 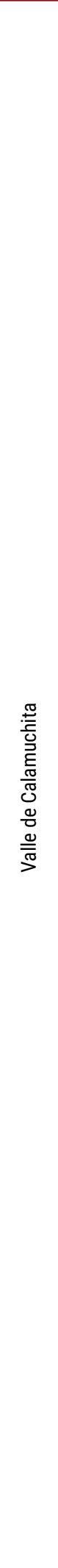 } & \multirow{3}{*}{ Potrero de Garay } & \multirow{3}{*}{$383 \pm 58$} & Poaceae & 26 \\
\hline & & & Prosopis sp. & 15 \\
\hline & & & $S / I$ & 6 \\
\hline & \multirow{4}{*}{ Potrero de Garay } & \multirow{4}{*}{$420 \pm 41$} & Poaceae & 6 \\
\hline & & & Prosopis sp. & 3 \\
\hline & & & Zea mays & 1 \\
\hline & & & $S / I$ & 5 \\
\hline & \multirow{5}{*}{$\begin{array}{l}\text { Sitio Loteo } 5 \text { - } \\
\text { Santa Rosa }\end{array}$} & \multirow{5}{*}{$533 \pm 42$} & Poaceae & 193 \\
\hline & & & Prosopis sp. & 35 \\
\hline & & & Geoffroea decorticans & 2 \\
\hline & & & Trithrinax campestris & 2 \\
\hline & & & $S / I$ & 45 \\
\hline & \multirow{6}{*}{$\begin{array}{c}\text { Constantinopla } \\
1215\end{array}$} & \multirow{6}{*}{$619 \pm 43$} & Poaceae & 222 \\
\hline & & & Prosopis sp. & 49 \\
\hline & & & Geoffroea decorticans & 19 \\
\hline & & & Trithrinax campestris & 2 \\
\hline & & & Zea mays & 2 \\
\hline & & & $S / I$ & 85 \\
\hline & \multirow{3}{*}{ Amboy } & \multirow{3}{*}{$830 \pm 20$} & Poaceae & 28 \\
\hline & & & Prosopis sp. & 4 \\
\hline & & & Zea mays & 1 \\
\hline & \multirow{5}{*}{ Potrero de Garay } & \multirow{5}{*}{$881 \pm 150$} & Poaceae & 66 \\
\hline & & & Prosopis sp. & 23 \\
\hline & & & Geoffroea decorticans & 2 \\
\hline & & & Zea mays & 1 \\
\hline & & & $S / I$ & 24 \\
\hline & \multirow{6}{*}{ Potrero de Garay } & \multirow{6}{*}{$889 \pm 59$} & Poaceae & 91 \\
\hline & & & Prosopis sp. & 1 \\
\hline & & & Geoffroea decorticans & 1 \\
\hline & & & Trithrinax campestris & 1 \\
\hline & & & Zea mays & 1 \\
\hline & & & $S / l$ & 8 \\
\hline & \multirow{6}{*}{ Potrero de Garay } & \multirow{6}{*}{$981 \pm 41$} & Poaceae & 136 \\
\hline & & & Prosopis sp. & 59 \\
\hline & & & Geoffroea decorticans & 7 \\
\hline & & & Trithrinax campestris & 1 \\
\hline & & & Zea mays & 4 \\
\hline & & & $S / I$ & 84 \\
\hline & \multirow{3}{*}{ Potrero de Garay } & \multirow{3}{*}{$995 \pm 161$} & Poaceae & 99 \\
\hline & & & Prosopis sp. & 7 \\
\hline & & & $\mathrm{S} / \mathrm{I}$ & 3 \\
\hline
\end{tabular}

Tabla 4. Número total de microrrestos vegetales recuperados de la muestra analizada para el valle de Calamuchita. 


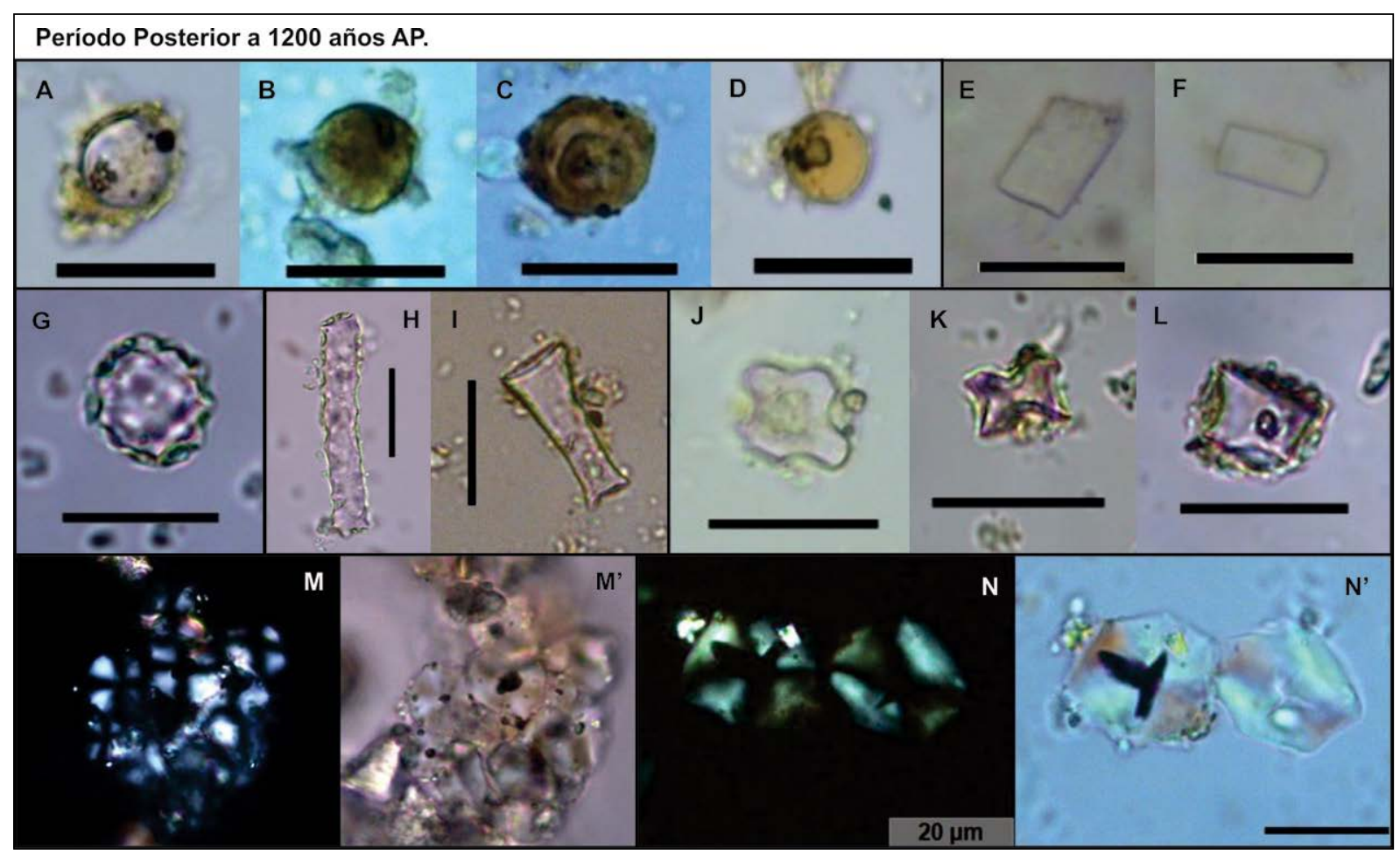

Figura 4. Microrrestos vegetales encontrados en el Valle de Calamuchita durante el POST 1200 años AP. A-D) silicofitolitos circulares; E-F) morfotipos poliédricos; G) silicofitolito esférico equinado; $H$ ) silicofitolito prismático; I) silicofitolito en forma de cono truncado; J) silicofitolito en forma de cruz; $K$ ) silicofitolito bilobado; L) Morfotipo wavy-top rondel; $M$ - $M^{\prime}$ ) granos de almidón aglomerados circulares y poligonales; $N$ - $\left.N^{\prime}\right)$ granos de almidón poligonales. Escala: $20 \mu \mathrm{m}$.

la discusión acerca de los cambios y continuidades en las estrategias adaptativas y los modos de vida de las poblaciones que habitaron la región serrana de la provincia de Córdoba durante el Holoceno tardío. A su vez, se destaca que para el valle de Calamuchita no existen antecedentes en el estudio de los recursos vegetales, por lo que estos resultados son novedosos en el campo de la arqueobotánica regional.

Las afinidades botánicas identificadas a partir del análisis de los microrrestos vegetales recuperados del tártaro dental humano, revelaron la presencia de elementos afines a la familia Poaceae, como así también a las subfamilias Panicoideae, Danthonioideae y Pooideae, los cuales quedaron retenidos durante la formación del cálculo al ingerir o manipular diversos tipos de plantas. A su vez, fue posible reconocer morfotipos relacionados con las especies Geoffroea decorticans ("chañar") y Trithrinax campestres ("palma caranday"), como así también al género Prosopis sp. ("algarrobo") en las muestras obtenidas para ambos períodos cronológicos. Esta información sugiere un consumo continuado de plantas silvestres independientemente de las condiciones climáticas. Este último género puede soportar grandes sequías y sobrevivir en suelos arenosos o salinos, logrando generar una mayor cantidad de frutos en momentos de aridez (Toledo, Correa y Beltramone, 2015). La información resulta relevante si consideramos que la reconstrucción paleoclimática realizada por Piovano y colaboradores (2009) sugiere una alternancia de las fases de frío y sequía, cuyo pico máximo se produjo alrededor de los 4700 años AP con alternancia de períodos fríos y secos y cálidos y húmedos, lo cual podría haber afectado no sólo la disponibilidad de los recursos alimenticios potencialmente seleccionados sino también su distribución.

Particularmente, el consumo y manipulación de los frutos de algarrobo (Prosopis sp.) ha sido ampliamente citado en estudios arqueológicos y etnobotánicos (Arias Toledo, 
Colantonio y Galetto, 2007; Giovannetti et al., 2008; López y Capparelli, 2014) con diferentes formas de ingesta (López, 2015) que demuestran su importancia como alimento tradicional en toda la región central del país (Capparelli, 2007). Su recolección se realizaba de manera estacional aprovechando la maduración progresiva durante el verano. En algunos casos, esta práctica estuvo acompañada por las estrategias de almacenamiento en pozos, ya que luego de aproximadamente 15 días el fruto entra en estado de putrefacción (Laguens y Bonnin, 2009). Los documentos históricos de los siglos XVI-XVII también presentan numerosas referencias al consumo y almacenamiento de estos frutos y su importancia en los grupos prehispánicos, con diferentes formas de cocción y preparación tendientes a disminuir la dureza y fibrosidad de los alimentos (Castro Olañeta, 2006; Gheggi, 2012).

En otras regiones, tales como Noroeste (NOA) y Noreste Argentinos (NEA) se han obtenido resultados similares, con alta presencia de macrorrestos de algarrobo (Prosopis sp.) que refuerzan su papel como alimento tradicional (Bonomo, Colobig y Mazzia, 2012; Capparelli y Lema, 2011; Colobig, Sánchez y Zucol, 2015; Oliszewski, 1999).

Por otra parte, los frutos del chañar (Geoffroea decorticans) proporcionan una contribución altamente nutritiva a la dieta (Figueroa y Dantas, 2006; Heider y López, 2016) y fueron empleados en la producción, principalmente, de jarabe y harina, como así también de bebidas alcohólicas como la "chicha" y la "aloja de chañar" (López, 2015 , 2017). En general sus frutos se pueden consumir hervidos o frescos, siendo directamente recolectados desde el árbol (Arias Toledo, 2009; Toledo et al., 2015).

Particularmente en el Valle de Punilla los elementos vegetales identificados en el tártaro dental sugieren que los morfotipos afines a Poáceas silvestres fueron los más abundantes $(\mathrm{N}=588)$. Al mismo tiempo, se hallaron numerosos microrrestos vegetales afines al algarrobo (Prosopis sp.) $-\mathrm{N}=90-\mathrm{y}$ chañar (Geoffroea decorticans) $-\mathrm{N}=21-$, en siete individuos datados entre los $2156 \pm 86$ y $387 \pm 41{ }^{14} \mathrm{C}$ años AP. Es de destacar, por primera vez, evidencia del manejo de palma caranday (Trithrinax campestris) $-\mathrm{N}$ = 5- en dos individuos de los sitios Ecoterra $\left(1881 \pm 39{ }^{14} \mathrm{C}\right.$ años AP) y Cuesta Blanca (1080 $\pm 40{ }^{14} \mathrm{C}$ años $\left.\mathrm{AP}\right)$.

Medina y colaboradores (2009), Medina y López (2007) y López (2015) hallaron en este valle macro y microrrestos de chañar (Geoffroea decorticans), algarrobo (Prosopis sp.) y Chenopodium sp./Amaranthus sp. en vasijas y artefactos de molienda con una antigüedad comprendida entre los 800 y 500 años AP. A su vez, Recalde y López (2017) encontraron en Pampa de Olaen, macrorrestos pertenecientes a porotos silvestres (Phaseolus vulgaris var aborigineus) con una antigüedad comprendida entre los 365 \pm 38 y $362 \pm 43{ }^{14} \mathrm{C}$ años AP. Las autoras vinculan estos hallazgos con un "continuum silvestre-domesticado" en el manejo de recursos vegetales (Recalde y López, 2017, p. 3). Es de suponer que las poblaciones asentadas en la región pudieron incorporar esta especie malezoide asociada a los cultivos como parte de sus prácticas productivas (Gremillion, 1993; López, 2017).

Para el valle de Traslasierra, se identificaron silicofitolitos de algarrobo (Prosopis sp.) $-\mathrm{N}=301-$, chañar (Geoffroea decorticans) $-\mathrm{N}=29-$, elementos vinculados a Poáceas $-\mathrm{N}=787-\mathrm{y}$ por primera vez, de palma caranday (Trithrinax campestris) $-\mathrm{N}=5-$, en tres individuos provenientes de los sitios Loma Bola $\left(954 \pm 85{ }^{14} \mathrm{C}\right.$ años AP), Copina (680 $\pm 40{ }^{14} \mathrm{C}$ años AP) y Cañada Larga (481 $\pm 57{ }^{14} \mathrm{C}$ años AP). Estos hallazgos resultan similares a las especies reportadas por Medina y colaboradores (2016), Pastor y colaboradores (2012-2014), López y colaboradores (2015) y López (2017), quienes para la misma zona, además de reportar macro y microrrestos afines a chañar (Geoffroea decorticans) encontraron evidencias de mistol (Ziziphus mistol) 
y quinoa (Chenopodium sp.) con antigüedades comprendidas entre los $2950 \pm 90$ y $750 \pm 70{ }^{14} \mathrm{C}$ años AP. Es interesante destacar que los estudios realizados por Medina y López (2007) en el Valle de Guasapampa, identificaron silicofitolitos de algarrobo (Prosopis sp.) y chañar (Geoffroea decorticans) en fragmentos de cerámica con una datación de $1360 \pm 60{ }^{14} \mathrm{C}$ años AP.

Previo a discutir la presencia de posibles plantas cultivadas en las muestras provenientes de los tres valles serranos, es necesario considerar que, en algunas ocasiones, se asume su existencia en los sitios arqueológicos, aun cuando los morfotipos hallados no permiten alcanzar ese grado de resolución, interpretando erróneamente la evidencia (Lema, 2017). La detección de formas silvestres antecesoras en el registro arqueológico coexistiendo con sus pares domésticos, como así también otras con caracteres intermedios, propone la existencia de un complejo "silvestre-cultivado-domesticado" (Lema, 2009; López y Andreoni, 2015). Aunque en el presente análisis no se encontró evidencia que pudiera afirmar la presencia de formas antecesoras silvestres de plantas cultivadas debido a la falta de caracteres diagnósticos que permitieran reconocerlas, no podemos descartar su posible existencia.

Si bien en el sector centro-oeste de la región serrana se ha documentado la presencia de fragmentos carbonizados de cotiledones correspondientes al poroto silvestre (Phaseolus vulgaris L. var. aborigineus) (Medina et al., 2014; Pastor, Medina y Berberián, 2013), estos hallazgos en el país son en general muy escasos, ya que la semilla se consume completamente (Babot, 2007; Oliszewski y Arreguez, 2015), siendo el único antecedente para la provincia de Córdoba un ejemplar recolectado en el año 1903 (Drewes, 2006). La existencia de plantas silvestres del género Phaseolus sp. fue señalada originalmente por Burkart (1941), quien indica que su crecimiento malezoide se produce en los bosques de alisos de Salta, Tucumán y Catamarca entre los 1.200 y 2.000 m s.n.m. La escasez de hallazgos y su aparición como malezas en otras ecorregiones nos hace suponer que los microrrestos vegetales encontrados en nuestras muestras pueden corresponder a una de las variedades cultivadas tales como Phaseolus vulgaris aff., var. vulgaris o Phaseolus cf $P$. lunatus.

Por otro lado, el posible ancestro silvestre de Cucurbita maxima (Cucurbita maxima subs. andreana) no se ha identificado en el registro arqueológico hasta el presente, excepto de manera tentativa en el sitio de Pampa de la Ventanilla ubicado en la costa central del Perú hacia 3000 años AP (Pearsall, 1992) y en el sitio arqueológico de Pampa Grande y Cueva de los Corrales 1 (provincia de Salta) alrededor de 500-600 años AP (Lema, 2009, 2011; Tarragó, 1980), conviviendo junto con su contraparte domesticada en complejos maleza-cultivo-domesticado (Korstanje, 2016; Lema, 2011, 2017). Esta situación podría ser interpretada como un intento de adaptar las formas silvestres a un tipo de ambiente diferente con el fin de lograr su domesticación (Lema, 2017). A su vez, el ancestro silvestre de Cucurbita moschata es aún desconocido (Sanjur, Piperno, Andres y Wessel-Beaver, 2002), lo que nos hace estimar que los morfotipos identificados en este trabajo corresponden a una de las dos especies cultivadas (Cucurbita moschata o Cucurbita maxima).

Respecto a las especies silvestres de papa, pertenecientes al género Solanum L. sect. petota Dumort., poseen una amplia distribución en nuestro país, citándose 18 especies diferentes (Clausen, Peralta y Spooner, 2013; Spooner, Álvarez, Peralta y Clausen, 2016). En el Dominio Chaqueño (Provincias Prepuneña, Monte, Pampeana, Chaqueña y Espinal) se encuentran 12 especies silvestres mientras que en las Provincias fitogeográficas del Espinal, Chaqueña y Pampeana encontramos las especies S. chacoense, S. commersonii y $S$. malmeanum, siendo $S$. chacoense la de mayor distribución en nuestro país y la cual se ha registrado en el Parque Nacional Quebrada del Condorito de la provincia de Córdoba (Clausen, Ispizua, Atencio, Calandroni y Digilio, 2018). 
En el valle de Calamuchita no existe evidencia previa de hallazgos arqueobotánicos, por lo cual, los resultados obtenidos en este trabajo son pioneros en el sector. Los mismos indicaron la presencia de algarrobo (Prosopis sp.) $-\mathrm{N}=196-$, chañar (Geoffroea decorticans) $-\mathrm{N}=31$ - y palma caranday (Trithrinax campestris) $-\mathrm{N}=4-$ con antigüedades comprendidas entre los $995 \pm 161$ y $383 \pm 58{ }^{14} \mathrm{C}$ años $\mathrm{AP}$, como así también un total de 867 elementos asociados a Poáceas.

Es interesante destacar que, en la zona de Pampa de Achala, Rivero (2007) y Rivero y López (2010) registraron silicofitolitos y granos de almidón afines a la subfamilia Pooideae provenientes de los instrumentos de molienda más antiguos datados hasta el momento (7108 $\pm 74{ }^{14} \mathrm{C}$ años AP), como así también granos de almidón afines a quinua (Chenopodium sp.). Los autores sugieren que los taxones más probables serían los salvajes como Chenopodium hircinum Schrad. o C. (= Disphania) ambrosioide (L.) Mosyakin y Clemants con una antigüedad cercana a los 3000 años AP. (López et al., 2015). A su vez, los daños observados en los granos de almidón asignados a estos taxones sugieren que las semillas habrían sido machacadas posiblemente para eliminar los pericarpios y su contenido de esteroides que les otorgan un sabor amargo y un efecto tóxico por la saponina que contienen (López, Capparelli y Nielsen, 2011).

Los estudios arqueobotánicos llevados adelante en el sector norte de la región serrana, revelaron la presencia de macrorrestos de mistol (Sarcomphalus mistol) y molle de beber (Lithraea molloides), los cuales presentaban modificaciones compatibles con el almacenamiento de sus frutos, como así también de chañar (Geoffroea decorticans), piquillín (Condalia sp.), algarrobo (Prosopis sp.) con evidencia de molienda, y aguaribay (Schinus areira) cuya distribución se encuentra circunscripta a esta zona (López, 2017; Recalde y López, 2017; Saur Palmieri, López y Trillo, 2018).

Por otro lado, si bien es arriesgado hablar de abundancias de determinados taxones para referirnos a la selección o preferencia de determinadas plantas considerando únicamente la evidencia alcanzada a partir los estudios sobre tártaro dental, las diferentes proporciones encontradas entre los mismos invita a realizar ciertas inferencias respecto de la importancia que pueden haber tenido las especies vegetales para estas poblaciones. En este sentido, podemos observar que, a lo largo de todo el Holoceno tardío, el consumo y manipulación de las plantas silvestres que actualmente se encuentran distribuidas tanto en la provincia Chaqueña como en la del Espinal, fue sostenido por parte de los grupos humanos que habitaron estos valles, particularmente aquellos referentes a los frutos de Prosopis sp. Esto permite sugerir que probablemente se hayan seleccionado con mayor frecuencia que otras especies vegetales también disponibles en la región, tales como chañar (Geoffroea decorticans), piquillín (Condalia sp.) o mistol (Ziziphus mistol). En este sentido, la hipótesis planteada por López (2017) y Recalde y López (2017) acerca de la sobrevaloración que se les otorga a los frutos del algarrobo (Prosopis sp.) en la vida de las poblaciones prehispánicas, no se sustenta con la evidencia encontrada en este estudio, donde la presencia de morfotipos afines al género indicaría que fue consumido en mayor abundancia que el resto de los recursos vegetales silvestres presentes en el entorno.

A su vez, la especie palma caranday (Trithrinax campestris) merece una mención especial debido a que se encontró, por primera vez, evidencia de silicofitolitos afines a las hojas de la misma en zonas donde actualmente su presencia no se encuentra documentada. La información sobre esta especie es limitada y hasta el momento sólo se ha registrado durante los análisis paleoecológicos, paleoambientales y arqueológicos de diferentes secuencias sedimentarias de la provincia de Entre Ríos (Bonomo et al., 2011; Patterer, 2014; Zucol y Brea, 2005). Su distribución en la actualidad abarca principalmente el noroeste de la provincia de Córdoba, particularmente los departamentos de Cruz del Eje, Ischilín, Minas, Pocho, Punilla, Río Seco, San Justo, 
Sobremonte, Totoral, Unión y Tulumba (Toledo et al., 2015). Su aparición en el tártaro dental de los individuos recuperados en los sitios arqueológicos de la región, en especial aquellos ubicados al sur de la provincia, con antigüedades comprendidas entre los 1881 \pm 39 y $533 \pm 42{ }^{14} \mathrm{C}$ años $\mathrm{AP}$, sugiere por un lado la posibilidad de que la distribución y disponibilidad de la especie hubiera sido mayor en el pasado, o bien de que se produjo un movimiento continuo por parte de estas poblaciones hacia regiones donde este recurso se encontraba accesible. Asimismo, la limitada cantidad de elementos silíceos recuperados vinculados a la palma caranday ( $0,38 \%$ del total de la muestra) puede corresponderse al consumo de sus frutos, los cuales suelen ser ingeridos tostados directamente sobre brasas (C. Bustos, comunicación personal, 2019¹) o con actividades relacionadas a procesos de manufactura (Pochettino, 2015) ya que se tradicionalmente se usa en cestería y en la construcción de casas (Correa, Toledo y Calandri, 2013). Esta actividad manifestaría la manipulación con los dientes de las fibras vegetales extraídas de sus hojas, práctica que, según la evidencia bioarqueológica, era habitual en los individuos de las sierras cordobesas, quienes presentan elevados índices de desgaste dental a lo largo de todo el Holoceno tardío y cuya variedad de formas y direcciones pueden estar indicando la realización de actividades paramasticatorias (González y Fabra, 2018).

Respecto a la evidencia disponible sobre la presencia de cultivos en la región central del país, se ha sugerido que los orígenes de la práctica hortícola pueden rastrearse en el Noroeste argentino, donde en momentos cercanos a los 2000 años AP. se estaban conformando varios sistemas de aldeas agrícolas, con cultivos a pequeña escala y prácticas alfareras (Laguens y Bonnin, 2009; Pastor, Medina, Recalde, López y Berberián, 2012). Pastor y colaboradores (2012-2014) proponen que el maíz encontrado en la región de Pampa de Achala, con una antigüedad datada en $2950 \pm 90$ años AP, posiblemente se haya obtenido a través del contacto con las sociedades agrícolas andinas. A su vez, también es posible que determinadas especies cultivadas se hayan incorporado desde la región Noreste del país, de la zona chaqueña, la cual posee una continuidad natural con las Sierras Centrales y presenta ciertas similitudes tales como las características ambientales y varios elementos materiales y tradicionales en común entre los pueblos tardíos (Laguens y Bonnin, 2009).

Según los aportes realizados por Laguens (1999), Laguens y Bonnín (2009) y Medina y colaboradores (2009), las poblaciones agroalfareras habrían diversificado el consumo y manipulación de los recursos silvestres disponibles en la zona, asumiendo que los mismos se consideran menos sensibles a los cambios ambientales que los productos cultivados. Es decir, que la incertidumbre respecto al resultado final de las cosechas posiblemente haya evitado una mayor dependencia de los mismos (Medina et al., 2014). En este sentido, la escasa evidencia de residencias a largo plazo y la poca inversión en los campos agrícolas, interpretados a partir de su desarrollo a pequeña escala y sin obras tales como canales de riego o construcción de terrazas de cultivo, respaldarían esta propuesta (Medina et al., 2016).

Las investigaciones arqueológicas realizadas por Laguens (1999) en el Noroeste de la provincia determinaron que para momentos posteriores a 2000 años AP la base agrícola cubría alrededor del $51 \%$ de la subsistencia, mientras que el $49 \%$ restante se encontraba dividido: un $32 \%$ para la recolección y un $17 \%$ para la caza. Estas estrategias de subsistencia se habrían organizado en torno al aprovechamiento de los diferentes ambientes para asegurar un aprovisionamiento anual más o menos constante. En esta línea, los trabajos de Laguens (1999), Medina y colaboradores (2014) y Fabra y González (2019) sugieren que el maíz no habría significado un aporte sustancial en la

1 Cristian Bustos es el Nahuan de la Comunidad Mampa Sacat, del Pueblo Sanaviron, ubicado en San José de la Dormida. Entrevista realizada en febrero en 2019. 
economía de las poblaciones tardías, a pesar del alto rendimiento potencial que podrían haber significado, en general, las plantas cultivadas. La evidencia del uso intensivo de ambientes poco favorables para el cultivo, como así también la abundante presencia de restos arqueofaunísticos y botánicos de origen silvestre, refuerzan esta teoría (López, 2017; Medina et al., 2016).

Por otro lado, López (2017) indica que, aunque las estrategias de subsistencia entre el sector norte y centro-oeste de la región serrana fueron similares, las diferencias en el manejo de los recursos vegetales habrían conducido a la formación de distintos paisajes, identificando por caso, un mayor número de taxones en el sector norte que en el centro-oeste. También señala la autora que los hallazgos de Solanum tuberosum se registraron en la zona norte, mientras que la evidencia de Cucurbita sp. se produjo en los valles de Traslasierra y Punilla del área centro-oeste con antigüedades comprendidas entre los $1028 \pm 40{ }^{14} \mathrm{C}$ años $\mathrm{AP} / 900 \pm 70{ }^{14} \mathrm{C}$ años $\mathrm{AP}$ y los $854 \pm 39{ }^{14} \mathrm{C}$ años $\mathrm{AP} / 525$ $\pm 36{ }^{14} \mathrm{C}$ años AP. Agrega que los tiempos de ocupación entre ambos sectores podrían haber sido diferentes, siendo más cortos en el sector centro-oeste y más prolongados en el sector norte. De esta manera se podría explicar la diferencia en las abundancias encontradas, debido a que una ocupación corta minimizaría el descarte de desechos con el fin de maximizar el escaso consumo de los recursos vegetales, mientras que en el área norte los frutos eran almacenados y se cultivaban en diferentes ciclos de crecimiento. Es interesante destacar que los resultados alcanzados en el presente trabajo señalaron la presencia de tres elementos almidonosos afines a Solanum tuberosum en dos sitios de Traslasierra: Guasmara $\left(920 \pm 20{ }^{14} \mathrm{C}\right.$ años AP) y Copina (680 $\pm 40{ }^{14} \mathrm{C}$ años AP), constituyendo la primera evidencia de consumo potencial de papa cultivada en la región centro-oeste de la provincia. Además, se hallaron microrrestos silíceos afines a Cucurbita sp. en el sitio Loma Bola ( $954 \pm 85{ }^{14} \mathrm{C}$ años AP) ubicado en el mismo valle con una antigüedad similar a la obtenida por López (2017).

Si bien las primeras observaciones de maíz (Zea mays) que se produjeron en los sitios Cruz Chiquita 3 en el valle de Traslasierra y Quebrada del Real 1, emplazado en Pampa de Achala, poseen una antigüedad aproximada de 3000 años (López, 2017; López et al., 2015; Pastor, Rivero, Recalde, Díaz y Truyol, 2017), no se encontraron evidencias que indiquen una producción agrícola local. Por este motivo, Pastor y colaboradores (2012) interpretan que una presencia tan temprana constituyó un aporte mínimo en la subsistencia de los grupos humanos y que su aparición posiblemente se encuentre más relacionada a su consumo como alimento exótico con un significado diferente al alimenticio. Asimismo, la evidencia más antigua comprobada de este recurso proviene de instrumentos de molienda del sitio Yaco Pampa 1, ubicado en el valle de Guasapampa con una datación de ca. 1300 años AP (López, 2015). Por otro lado, tanto los porotos cultivados (comunes: Phaseolus vulgaris var. vulgaris, pallar: Phaseolus cf. lunatus) como la calabaza (Cucurbita sp.), posiblemente la papa cultivada (Solanum sp.), la batata o camote (cf. Ipomoea batata) y la mandioca (cf. Manihot sp.), fueron incorporados en momentos posteriores a los 1500-1100 años AP (López, 2017; Medina et al., 2014; Recalde y López, 2017).

Los microrrestos vegetales recuperados en este estudio poseen para el maíz (Zea mays) una cronología más tardía en los tres valles considerados, con antigüedades comprendidas entre los $1080 \pm 40{ }^{14} \mathrm{C}$ años AP y $387 \pm 41{ }^{14} \mathrm{C}$ años AP. La posible presencia de poroto común (Phaseolus vulgaris) fue registrada en los valles de Traslasierra y Punilla: en el primer caso, se identificaron siete granos de almidón en un individuo datado en $920 \pm 20{ }^{14} \mathrm{C}$ años AP proveniente del sitio Loma Bola, mientras que, en el segundo, se encontraron tres elementos almidonosos en un individuo con una edad estimada de $387 \pm 41{ }^{14} \mathrm{C}$ años AP correspondiente al sitio Nunsacat. En el valle de Traslasierra también se registró la presencia de silicofitolitos afines al zapallo (Cucurbita sp.) en un individuo proveniente del sitio Loma Bola (954 $\pm 85{ }^{14} \mathrm{C}$ años AP) 
y granos de almidón asociados posiblemente a la papa cultivada (Solanum tuberosum) en dos individuos del sitio Guasmara $\left(920 \pm 20{ }^{14} \mathrm{C}\right.$ años AP) y Copina $\left(680 \pm 40{ }^{14} \mathrm{C}\right.$ años AP). Las cronologías obtenidas para los géneros Phaseolus sp. y Cucurbita sp. son coincidentes con las encontradas en trabajos previos, sin bien no se pudo identificar la presencia de otros taxones frecuentemente localizados como Ipomoea batata y Manihot sp.

Con respecto a la representatividad de los diferentes taxones silvestres y cultivados que fueron identificados en el presente trabajo, los mismos indican que los porcentajes de aquellos morfotipos vinculados con las plantas silvestres que fueron consumidas y/o manipuladas, son similares a lo largo de todo el Holoceno tardío. Es así como los valores obtenidos para el algarrobo (Prosopis sp.) y el chañar (Geoffroea decorticans) en momentos previos a 1200 años AP son de $10,44 \%$ y $3,32 \%$ respectivamente, mientras que para momentos posteriores observamos valores del 9,34\% para el género y de $2,02 \%$ para la especie. Asimismo, aquellos elementos afines a Palma Caranday (Trithrinax campestris) representaron el $0,47 \%$ de la muestra en momentos previos al 1200 y un $0,46 \%$ durante el período posterior (Tabla 5). Por otro lado, el porcentaje asociado a las plantas probablemente cultivadas representa únicamente el $3 \%$ del total de microrrestos vegetales identificados en las muestras correspondientes al POST 1200.

\begin{tabular}{|c|c|c|c|}
\hline \multicolumn{2}{|c|}{ Pre 1.200 } & \multicolumn{2}{c|}{ Post 1.200 } \\
\hline Prosopis sp. & $10,44 \%$ & Prosopis sp. & $9,34 \%$ \\
Geoffroea decorticans & $3,32 \%$ & Geoffroea decorticans & $2,02 \%$ \\
Trithrinax campestris & $0,47 \%$ & Trithrinax campestris & $0,46 \%$ \\
& & Plantas cultivadas & $3 \%$ \\
\hline
\end{tabular}

Tabla 5. Porcentajes de plantas silvestres y cultivadas identificadas en el sector serrano de la provincia de Córdoba a lo largo del Holoceno tardío.

\section{Conclusiones}

A modo de síntesis, podemos mencionar que se halló evidencia de manipulación de plantas silvestres tales como el algarrobo (Prosopis sp.), chañar (Geoffroea decorticans) y Palma Caranday (Trithrinax campestris) con antigüedades comprendidas entre los $2707 \pm 61$ y $383 \pm 58{ }^{14} \mathrm{C}$ años AP. Estos hallazgos fueron documentados a lo largo de todo el Holoceno tardío, lo cual indicaría que la práctica de recolección de frutos silvestres continuó realizándose aún después de la incorporación de las plantas cultivadas, cuyo registro más antiguo data de $1080 \pm 40{ }^{14} \mathrm{C}$ años AP con la presencia de maíz (Zea mays), y una posterior incorporación del zapallo (Cucurbita sp.), porotos (Phaseolus vulgaris) y papa (Solanum tuberosum) hacia los 900 años AP.

A partir de los resultados obtenidos del análisis de los microrrestos vegetales hallados en las muestras de tártaro dental humano, sugerimos una continuidad en la selección, consumo y manipulación de plantas silvestres en la región serrana a lo largo de todo el Holoceno tardío y un cambio a partir de los 1200 años AP aproximadamente, con la incorporación de recursos vegetales cultivados, si bien los mismos se registraron en un porcentaje considerablemente menor en comparación con los silvestres.

De nuestros hallazgos, la evidencia más temprana de vegetales cultivados en la dieta corresponde al valle de Punilla con una antigüedad estimada de $1080 \pm 40{ }^{14} \mathrm{C}$ años 
AP, a partir de la observación de granos de almidón afines a Zea mays. Más tarde, en el Valle de Traslasierras, se habrían agregado otros cultivos tales como Cucurbita sp., Phaseolus sp. y Solanum sp. entre los $954 \pm 85$ y $920 \pm 20{ }^{14} \mathrm{C}$ años AP.

La variabilidad de taxones identificados nos sugiere que las sociedades humanas tenían conocimiento acerca de su entorno y aprovecharon de manera exitosa los beneficios otorgados por los recursos vegetales disponibles en el medio circundante. Consecuentemente, podemos suponer que se tomaron decisiones tendientes a seleccionar aquellas especies vegetales que pudieran resultar más beneficiosas como fuente de alimento o ventajosas desde un punto de vista tecnológico (Pochettino, 2015).

Los resultados revelaron que, así como el algarrobo - principalmente- y el chañar, fueron las plantas silvestres más frecuentemente identificadas en el registro, el maíz representa el recurso cultivado que más comúnmente se encuentran en las muestras posteriores a 1200 años AP. La aparición de estos morfotipos silíceos y almidonosos podría reflejar una transición desde economías basadas en la recolección hacia aquellas productivas, que habría llevado a la implementación un sistema hortícola incipiente, lo que no necesariamente podría relacionarse con un cambio social importante sino con una modificación en las prácticas que, al menos en un principio, se habrían dado a pequeña escala (Lema, 2010) y de manera complementaria a la caza y recolección.

La existencia de una economía mixta podría deberse a estrategias adoptadas por las poblaciones que habitaron la región serrana, ante el aumento demográfico, la escasez de recursos o incluso la llegada de los españoles que provocó una desestructuración en la forma de vida de estos grupos humanos (Laguens y Bonnin, 2009). Aun así, se debe tener en cuenta que las identificaciones alcanzadas en este trabajo representan sólo una pequeña porción de la variabilidad de plantas potencialmente consumidas en el pasado.

\section{Agradecimientos}

Las autoras desean agradecer a los siguientes museos públicos que permitieron el acceso a sus colecciones: Museo de Antropología (FFyH, UNC), Museo Capitán Juan de Zevallos (Valle Hermoso), Museo Comechingón (Mina Clavero) y Museo Dr. Dalmacio Vélez Sarsfield (Amboy). También agradecemos a Cristian Bustos, de la Comunidad Mampa Sacat Sanaviron, por compartir su conocimiento sobre el uso de especies nativas por los pueblos indígenas de la región y a los evaluadores anónimos por sus valiosas sugerencias y contribuciones que han mejorado significativamente la versión original del manuscrito. Este trabajo fue financiado por los siguientes proyectos FONCyT PICT 2015-3155 y SeCyT UNC 2016-2017. 


\section{Referencias citadas}

» Arias Toledo, B. (2009). Diversidad de usos, prácticas de recolección y diferencias según género y edad en el uso de plantas medicinales en Córdoba. Argentina. Boletín Latinoamericano y del Caribe de Plantas Medicinales y Aromáticas, 5(8), 389-401.

» Arias Toledo, B., Colantonio, S. y Galetto, L. (2007). Knowledge and use of edible and medicinal plants in two communities from the Chaco Forest, Córdoba Province, Argentina. Journal of Ethnobiology, 27(2), 218-232. https://doi.org/10.2993/0278-0771(2007)27[218:KAUOEA]2.0. $\mathrm{CO} ; 2$

» Babot, M. P. (2003). Starch grain damage as an indicator of food processing. En D. M. Hart y L. A. Wallis (Eds.), Phytolith and starch research in the Australian-Pacific-Asian regions: The state of the art (pp. 69-81). Canberra: Pandanus Books.

» Babot, M. P. (2007). Granos de almidón en contextos arqueológicos: Posibilidades y perspectivas a partir de casos del Noroeste argentino. En B. Marconetto, M. P. Babot y N. Oliszewski (Eds.), Paleoetnobotánica del Cono Sur: estudios de casos y propuestas metodológicas (pp. 95-125). Córdoba: Ferreyra.

» Babot, M. P., Oliszewski, N. y Grau, A. (2007). Análisis de caracteres macroscópicos y microscópicos de Phaseolus vulgaris (Fabaceae, Faboideae) silvestres y cultivados del Noroeste argentino. Una aplicación en arqueobotánica. Darwiniana, 45(2), 149-162.

» Benvenuto, M. L., Honaine, M. F., Osterrieth, M. L. y Morel, E. (2015). Differentiation of globular phytoliths in Arecaceae and other monocotyledons: morphological description for paleobotanical application. Turkish Journal of Botany, 39(2), 341-353. http://sedici.unlp.edu. ar/handle/10915/101654

» Berberián, E. (1999). Las Sierras Centrales. Nueva Historia de la Nación Argentina. Buenos Aires: Planeta.

» Bertoldi de Pomar, H. (1971). Ensayo de clasificación morfológica de los silicofitolitos. Ameghiniana, 8(3-4), 317-328.

» Bertoldi de Pomar, H. (1975). Los silicofitolitos: sinopsis de su conocimiento. Darwiniana, 19(24), 173-206.

» Bonomo, M., Colobig, M. M. y Mazzia, N. (2012). Análisis de residuos orgánicos y microfósiles silíceos de la "cuchara" de cerámica del sitio 1 arqueológico Cerro Tapera Vázquez (Parque Nacional Pre-Delta, Argentina). Revista do Museu de Arqueologia e Etnologia, 22, 31-50.

» Bonomo, M., Politis, G. y Gianotti García, C. (2011). Montículos, jerarquía social y horticultura en las sociedades indígenas del Delta del río Paraná (Argentina). Latin American Antiquity, 22(3), 297-333. https://doi.org/10.7183/1045-6635.22.3.297

» Burkart, A. (1941). Sobre la existencia de razas silvestres de Phaseolus vulgaris y $P$. lunatus en el Norte argentino. Primera Reunión Argentina de Agronomía, 52.

» Cabido, M., Carranza, M. L., Acosta, A. y Páez, S. (1991). Contribución al conocimiento fitosociológico del Bosque Chaqueño Serrano en la provincia de Córdoba, Argentina. Phytocoenología, 19(4), 547-566.

» Cabido, M. y Zak, M. (1999). Vegetación del Norte de Córdoba. Córdoba: Secretaría de Agricultura, Ganadería y Recursos Renovables de Córdoba.

»Cabrera, A. L. (1976). Regiones fitogeográficas argentinas. Enciclopedia Argentina de Agricultura y Jardinería, Tomo II, Fascículo 2 (pp. 1-85). Buenos Aires: Acme.

»Canals Frau, S. (1953). Las Poblaciones Indígenas de la Argentina. Buenos Aires: Editorial Sudamericana. 
» Capparelli, A. (2007). Los productos alimenticios derivados de Prosopis chilensis (Mol.) Stuntz y P. flexuosa DC, Fabaceae, en la vida cotidiana de los habitantes del NOA y su paralelismo con el algarrobo europeo. Kurtziana, 33(1), 1-19.

» Capparelli, A. y Lema, V. (2011). Recognition of postharvest processing of algarrobo (Prosopis spp.) as food from two sites of Northwestern Argentina: An ethnobotanical and experimental approach for desiccated macroremains. Archaeological and Anthropological Sciences, 3(1), 71-92.

» Cassiodoro, G., Rindel, D., Goñi, R., Re, A., Tessone, A., García Guraieb, S., Belardi, J., Espinosa, S., Nuevo Delaunay, A., Dellepiane, J., Flores Coni, J., Guichón, F., Martínez, C. y Pasqualinin, S. (2013). Arqueología del Holoceno medio y tardío en Patagonia meridional: Poblamiento Humano y fluctuaciones climáticas. Diálogo Andino, 41, 5-23. http://dx.doi.org/10.1007/ s12520-011-0052-5

» Castro Olañeta, I. (2006). Transformaciones y continuidades de las sociedades indígenas en el sistema colonial. El pueblo de indios de Quilino a principios del siglo XVII. Córdoba: Alción Editora.

» Cingolani, A. M., Renison, D., Zak, M. R. y Cabido, M. R. (2004). Mapping vegetation in a heterogeneous mountain rangeland using landsat data: an alternative method to define and classify land-cover units. Remote Sensing of Environment, 92(1), 84-97.

»Cioccale, M. (1999). Climatic fluctuations in the Central Region of Argentina in the last 1000 years. Quaternary International, 62, 35-47.

» Clausen, A. M., Ispizua, V. N., Atencio, H. M., Calandroni, M. y Digilio, A. (2018). Especies silvestres de papa (Solanum sect. Petota y sect. Etuberosum) identificadas en áreas protegidas de la Argentina. Boletín de la. Sociedad Argentina de Botánica, 53(1), 67-75.

»Clausen, A. M., Peralta, I. E. y Spooner, D. M. (2013). Grupo VIII. Potato. En A. M. Anton y F. O. Zuloaga (Eds.), Flora Argentina (Flora Vascular de la República Argentina) (pp. 264-289). Buenos Aires: IOBDA- IMBIV, CONICET.

» Colobig, M. M. (2014). Estado actual del estudio de fitolitos en contextos arqueológicos de Argentina. Scientia Interfluvius, 5(1), 7-30.

» Colobig, M. M., Sánchez, J. y Zucol, A. F. (2015). Análisis de macrorrestos vegetales en el sitio arqueológico Los Tres Cerros 1 (Isla las Moras, Victoria, Entre Ríos). Revista del Museo de Antropología, 8(1), 115-124.

" Correa, A., Toledo, J. y Calandri, E. (2013). Estudio químico de los frutos de la "Palma Caranday" (Trithrinax campestris) y su posible uso como recurso alimenticio. Trabajo presentado en el III Congreso de alimentos en el Siglo XXI. Mendoza, Argentina.

» Cortella, A. y Pochettino, M. (1994). Starch grain analysis as a microscopic diagnostic feature in the identification of plant material. Economic Botany, 48(2), 171-181.

»De Aparicio, F. (1936). La antigua provincia de los Comechingones. En Junta de Historia y Numismática (Eds.), Historia de la Nación Argentina, Tomo I (pp. 389-428). Buenos Aires: Imprenta de la Universidad.

"Drewes, S. I. (2006). On Phaseolus vulgaris var. aborigineus (Fabaceae) in Córdoba. Boletín de la Sociedad Argentina de Botánica, 41(3-4), 323-324.

» Fabra, M. y Demarchi, D. (2013). Análisis morfogeométrico aplicado al estudio de los patrones espaciales y temporales de variación morfológica craneofacial en poblaciones del centro de Argentina. Cuadernos del Instituto Nacional de Pensamiento Latinoamericano, 1(1), 87-101.

»Fabra, M. y González, C. V. (2015). Diet and oral health of populations that inhabited central Argentina (Córdoba province) during late Holocene. International Journal of Osteoarchaeology, 25(2), 160-175. https://onlinelibrary.wiley.com/doi/abs/10.1002/oa.2272

» Fabra, M. y González, C. V. (2019). Oral health, diet and social change in populations of the region of central Argentina during Late Holocene: Bioarchaeological and isotopic evidence. Latin American Antiquity, 30(4), 818-835.

» Fabra, M., Salega, S. y González, C. V. (2009). Comportamiento mortuorio en poblaciones prehispánicas de la región austral de las Sierras Pampeanas durante el Holoceno. Arqueología, $15,165-186$. 
» Figueroa, G. y Dantas, M. (2006). Recolección, procesamiento y consumo de frutos silvestres en el noroeste semiárido argentino. Casos actuales con implicancias arqueológicas. La Zaranda de Ideas. Revista de Jóvenes Investigadores en Arqueología, 2, 35-50.

» Gallego, L y Distel, R. (2004). Phytolith Assemblages in Grasses Native to Central Argentina. Annals of Botany, 94, 865-874.

» Gheggi, M. S. (2012). Patologías orales, dieta y modo de vida en Esquina de Huajra (Quebrada de Humahuaca, Jujuy). Revista Argentina de Antropología Biológica, 14(1), 65-77.

» Giorgis, M. A., Cabido, M. y Cingolani, A. (2011). Caracterización florística y estructural del Bosque Chaqueño Serrano. Berlín: Editorial Académica Española (EAE).

» Giovannetti, M. A., Lema, V. S, Bartoli, C. G. y Capparelli, A. (2008). Starch grain characterization of Prosopis chilensis (Mol.) Stuntz and P. flexuosa DC, and the analysis of their archaeological remains in Andean South America. Journal of Archaeological Science, 35(11), 2973-2985.

» González, C. V. y Fabra, M. (2018). Desgaste dental y hábitos dietarios en poblaciones arqueológicas del centro de Argentina. Arqueología, 24(2), 133-159.

» Gremillion, K. (1993). The evolution of seed morphology in domesticated Chenopodium: an archaeological case study. Journal of Ethnobiology, 13(21), 149-169.

» Heider, G. y López, M. L. (2016). El consumo de recursos vegetales silvestres en grupos Cazadores Recolectores del Norte de Pampa Seca (San Luis y Córdoba, Argentina). Mundo de Antes, 10, 73-99.

» Henry, A. y Piperno, D. (2008). Using plant microfossils from dental calculus to recover human diet: A case study from Tell al-Raqa'i, Syria. Journal of Archaeological Science, 35(7), 1943-1950.

» Henry, A., Hudson, H. F. y Piperno, D. (2009). Changes in starch grain morphologies from cooking. Journal of Archaeological Science, 36(3), 915-922.

» ICSN (2011). The International Code for Starch Nomenclature, http://www.fossilfarm.org/ ICSN/Code.html. (Acceso: 26 de octubre, 2019).

» Korstanje, M. A. (2016). Arqueobotánica relatada del noroeste argentino: lo que nos contaron las plantas domesticadas en los últimos 30 años. Cadernos do Lepaarq, 25(13), 304-331.

» Korstanje, M. A. y Babot, M. P. (2007). Microfossils characterization from south Andean economic plants. En M. Madella y D. Zurro (Eds.), Plants, people and places. Recent studies in phytolith analysis (pp. 41-72). Oxford: Oxbow books.

»Laguens, A. (1999). Arqueología del contacto hispano-indígena. Un estudio de cambios y continuidades en las Sierras Centrales de Argentina. Oxford: BAR International Series 801.

» Laguens, A. y Bonnin, M. (2009). Sociedades indígenas de las Sierras Centrales. Arqueología de Córdoba y San Luis. Córdoba: Universidad Nacional de Córdoba.

» Laguens, A., Fabra, M., Dos Santos, G. y Demarchi, D. (2009). Paleodietary inferences based on isotopic evidences for populations of the Central Mountains of Argentina during the Holocene. International Journal of Osteoarchaeology, 19(2), 237-249. https://doi.org/10.1002/oa.1064

»Lema, V. (2009). Domesticación Vegetal y Grados de Dependencia Ser Humano-Planta en el Desarrollo Cultural Prehispánico del Noroeste Argentino. (Tesis Doctoral inédita), Universidad Nacional de La Plata, Argentina.

» Lema, V. (2010). Procesos de domesticación vegetal en el pasado prehispánico del noroeste argentino: Estudio de las prácticas más allá de los orígenes. Relaciones de la Sociedad Argentina de Antropología, XXXV, 121-142.

» Lema, V. (2011). Lo micro en lo macro: el tratamiento microscópico de macrorestos vegetales para la identificación de prácticas y modos de relación con el entorno vegetal en el estudio arqueológico de la domesticación vegetal. Arqueología, 17, 57-79.

» Lema, V. (2017). Geografías y prácticas: plantas que circulan, que se quedan y que se van para no volver. En B.N, Ventura, G. Ortiz y M.B. Cremonte (Eds.), Arqueología de la vertiente oriental Surandina. Interacción macro-regional, materialidades, economía y ritualidad (pp. 267-278). Ciudad Autónoma de Buenos Aires: Sociedad Argentina de Antropología. 
» López, M. L. (2015). La cocina como medio para la reproducción social de los grupos prehispánicos de las sierras de Córdoba. En J. Salazar (Ed.), Condiciones de posibilidad de la reproducción social en sociedades prehispánicas y coloniales tempranas en las Sierras Pampeana (pp. 177-212). Córdoba: CEH Prof. Carlos S.A. Segreti.

» López, M. L. (2017). Archaeobotany in central Argentina: macro- and microscopic remains at several archaeological sites from early Late Holocene to early colonial times (3,000-250 BP). Vegetation History and Archaeobotany, 27, 219-228. https://dx.doi.org/10.1007/s00334-017$\underline{0627-x}$

» López, M. L. y Andreoni, D. F. (2015). Estudios arqueobotánicos en Argentina. Situación actual y nuevas perspectivas. Comechingonia, Revista de Arqueología, 19(2), 11-17.

» López, M. L y Capparelli, A. (2014). Algarrobo pods (Prosopis sp., leguminoseae) in the Central and Northwestern Argentina. Food-traditional products and technological innovations involved in their manufacture. Trabajo presentado en el VI Congreso Internacional de Etnobotánica (ICEB), Córdoba, España.

» López, M. L., Capparelli, A. y Nielsen, A. (2011). Traditional post harvest processing to make quinoa grains (Chenopodium quinoa var quinoa) apt for consumption in Northern Lipez (Potosí, Bolivia): ethnoarchaeological and archaeobotanical analyses. Journal of Archaeological and Anthropological Sciences, 3(1), 49-70.

» López, M. L., Medina, M. y Rivero, D. (2015). First records of Chenopodium spp./Amaranthus spp. starch grains and their relevance to the study of the Late Holocene human subsistence in Central Argentina. Holocene, 25, 288-295. http://dx.doi.org/10.1177/0959683614558652

» Luti, R., Solis, M., Galera, F., De Ferreyra, N. M., Berzal, M., Nores, M., Herrera, M. y Barrera, J. (1979). Vegetación. En J. Vázquez, R. Miatello y E. Roqué (Eds.), Geografía Física de la Provincia de Córdoba (pp. 297-367). Buenos Aires: Boldt.

» Medina, M. y López, M. L. (2007). Arqueobotánica del Sitio Puesto La Esquina 1 (Pampa de Olaen, Córdoba): Resultados Preliminares. Trabajo presentado en el XVI Congreso Nacional de Arqueología Argentina. San Salvador de Jujuy, Argentina.

» Medina, M., López, L. y Berberián, E. (2009). Agricultura y recolección en el Tardío Prehispánico de las Sierras de Córdoba (Argentina): el registro arqueobotánico de C.Pun.39. Arqueología, $15,217-230$

» Medina, M., Pastor, S. y Berberián, E. (2014). "Es Gente Fazil de Moverse de una Parte a Otra". Diversidad en las Estrategias de Subsistencia y Movilidad Prehispánicas Tardías (Sierras de Córdoba, Argentina). Complutum, 25(1), 73-88.

» Medina, M., Pastor, S. y Recalde, A. (2016). The archaeological landscape of Late Prehispanic mixed foraging and cultivation economy (Sierras of Cordoba, Argentina). Journal of Anthropological Archaeology, 42, 88-104. https://doi.org/10.1016/j.jaa.2016.04.003

» Musaubach, M. G. (2012). Potencialidad de estudios arqueobotánicos sobre tártaro dental de cazadores recolectores de la provincia de La Pampa, Argentina. Revista Argentina de Antropología Biológica, 14, 105-113.

» Neumann, K., Strömberg, C., Ball, T., Albert, R., Vrydaghs, L y Scott Cummings, L. (2019). International Code for Phytolith Nomenclature (ICPN) 2.0. Annals of Botany, XX, 1-11.

» Oliszewski, N. (1999). La importancia del algarrobo en Campo del Pucará (Andalgalá, Catamarca) durante el Período Formativo. En C. Aschero, A. Korstanjey y P. Vuoto (Eds.), Los tres reinos: prácticas de recolección en el Cono Sur de América (pp. 171-177). San Miguel de Tucumán: Magna Publicaciones.

»Oliszewski, N. y Arreguez, G. (2015). Manejo de recursos vegetales alimenticios en la quebrada de los Corrales, El Infiernillo, Tucumán (2100-1550 años AP.). Comechingonia. Revista de Arqueología, 19(2), 111-140.

» Oyarzabal, M., Clavijo, J., Oakley, L., Biganzoli, F., Tognetti, P., Barberis, I., Maturo, H.M., Aragón, R., Campanello, P. I., Prado, D., Oesterheld, M. y León, R. J. C. (2018). Unidades de vegetación de la Argentina. Ecología Austral, 28, 40-63. 
» Pastor, S y Berberián, E. (2007). Arqueología del sector central de las Sierras de Córdoba (Argentina). Hacia una definición de los procesos sociales del período prehispánico tardío (900-1573 DC). Intersecciones en Antropología, 8(8), 31-47.

»Pastor, S. y López, M. L. (2010). Consideraciones sobre la agricultura prehispánica en el sector central de las Sierras de Córdoba. En A. Korstanje y M. Quesada (Eds.), Arqueología de la Agricultura: Casos de Estudio en la Región Andina Argentina (pp. 208-233). Tucumán: Magma.

» Pastor, S., López, M. L. y Rivero, D. (2012-2014). Access to maize (Zea mays) and its manipulation in hunter-gatherer context in central Argentina (ca. 3000-2500 BP). Before Farming, 4, 1-10.

» Pastor, S., Medina, M. y Berberián, E. (2013). Poblados, casas y maizales. Arqueología del espacio residencial y productivo en las Sierras Centrales de Argentina (ca. 1100-300 AP). Revista Española de Antropología Americana, 43(1), 31-55.

» Pastor, S., Medina, M., Recalde, A., López, L. y Berberián, E. (2012). Arqueología de la región montañosa central de Argentina. Avances en el conocimiento de la historia prehispánica tardía. Relaciones de la Sociedad Argentina de Antropología, XXXVII(1), 89-112.

» Pastor, S., Rivero, D., Recalde, A., Díaz, I. y Truyol, G. (2017). Procesos y paisajes sociales en las Sierras Centrales de Argentina durante el Holoceno tardío inicial (ca. 4200-2000 años AP). Relaciones de la Sociedad Argentina de Antropología, XLII(2), 281-303.

» Patterer, N. (2014). Análisis fitolíticos de las principales especies de palmeras (Arecaceae) presentes en regiones subtropicales de América del Sur. Boletín. Sociedad Argentina de Botanica, 49(4), 491-502.

» Pearsall, D. (1992). The origins of plant cultivation in South America. En C. Wesley Cowan y P.J. Watson (Eds.), The Origins of Agriculture: An International Perspective (pp. 173-205). Washington D. C. y Londres: Smithsonian Institution Press.

» Pearsall, D., Chandler-Ezell, K y Chandler-Ezell, A. (2003). Identifying maize in neotropical sediments and soils using cob phytoliths. Journal of Archaeological Science, 30, 611-627.

» Pearsall, D., Chandler-Ezell, K. y Zeidler, J. A. (2004). Maize in ancient Ecuador: results of residue analysis of stone tools from the Real Alto site. Journal of Archaeological Science, 31, 423-442.

» Piovano, L. E., Ariztegui, D., Córdoba, F., Cioccale, M. y Sylvestre, F. (2009). Hydrological variability in South America below the tropic of Capricorn (Pampas and Patagonia, Argentina) during the last 13.0 ka. En F. Vimeux, F. Sylvestre y M. Khodri M (Eds.), Past climate variability in South America and surrounding regions. Developments in Paleoenvironmental Research 14 (pp. 323-351). Dordrecht: Springer

» Piperno, D. (2006). Phytoliths. A Comprehensive Guide for Archaeologist and Paleoecologist. Estados Unidos: Altamira Press.

» Pochettino, M. L. (2015). Botánica económica: las plantas interpretadas según tiempo, espacio y cultura (1 ra edición). Ciudad Autónoma de Buenos Aires: Sociedad Argentina de botánica.

» Recalde, A. y López, M. L. (2017). Las Sociedades Prehispánicas Tardías En La Región Septentrional Del Centro De Argentina (Sierras Del Norte, Córdoba). Avances A Su Conocimiento Desde Los Recursos Vegetales. Chungara, Revista de Antropología Chilena, 49(4), 1-16. http://dx.doi.org/10.4067/S0717-73562017005000109

» Riccardi, C. 1995. Paleoclima. Cambio Global. Publicación especial de la Academia Nacional de Geografía, 10, 91-126.

» Rivero, D. (2007). ¿Existieron cazadores-recolectores no igualitarios en las Sierras Centrales de Argentina? Evaluación del registro arqueológico. En A. Nielsen, V. Seldes, M. Vázquez y P. Mercolli (Eds.), Procesos Sociales Prehispánicos en el Sur Andino. La vivienda, la comunidad y el territorio (pp. 347-359). Córdoba: Editorial Brujas.

» Rivero, D. y López, M. L. (2010). Procesamiento de vegetales durante el Holoceno Temprano en las sierras de Córdoba (ca. 7100 AP). Primera aproximación. Trabajo presentado en el XVII Congreso Nacional de Arqueología Argentina. Mendoza, Argentina. 
»Sanjur, O., Piperno, D., Andres, T. y Wessel-Beaver, L. (2002). Phylogenetic relationships among domesticated and wild species of Cucurbita (Cucurbitaceae) inferred from a mitochondrial gene: Implications for crop plant evolution and areas of origin. Proceedings of the National Academy of Sciences, 99(1), 535-540.

» Saur Palmieri, V., López, M. L. y Trillo, C. (2018). Aproximaciones etnobotánicas de las especies y prácticas de frutos nativos comestibles de la actualidad. Aportes para la interpretación del pasado prehispánico de Cerro Colorado (Córdoba, Argentina). Boletín de la Sociedad Argentina de Botánica, 53(1), 115-133.

»Spooner, D. M., Álvarez, N., Peralta, I. E. y Clausen, A. M. (2016). Taxonomy of wild potatoes and their relatives in Southern South America (Solanum sects. Petota and Etuberosum). Systematic botany monographs: monographic series of The American Society of Plant Taxonomists, 100, 240.

» Tarragó, M. N. (1980). El proceso de agriculturización en el noroeste argentino, zona valliserrana. Trabajo presentado en el V Congreso Nacional de Arqueología Argentina. San Juan, Argentina.

» Tavarone, A., Colobig, M. y Fabra, M. (2019). Late Holocene plant use in lowland central Argentina: Microfossil evidence from dental calculus. Journal of Archaeological Science: Reports, 26, 1-12. https://doi.org/10.1016/j.jasrep.2019.101895

» Toledo, J. M., Correa, A. y Beltramone, G. (2015). Frutos comestibles nativos de la provincia de Córdoba, Argentina. Córdoba: Advocatus, Universidad Blas Pascal.

» Twiss, P. C. (1992). Predicted world distribution of C3 and C4 grass phytoliths. En G. Rapp y S. C. Mulholland (Eds.), Phytoliths Systematics. Emerging Issues Advances in Archaelogical and Museum Science 1 (pp. 113-128). Londres: Plenum Press.

»Zucol, A. F. (1999). Fitolitos de las Poaceae argentinas. IV. Asociación fitolítica de Cortaderia selloana (Danthonieae: Arundinoideae), de la provincia de Entre Ríos (Argentina). Natura Neotropicalis, 30, 25-33.

»Zucol, A. F y Brea, M. (2005). Phytolith systematics, guideline for a classificatory system. A study case in the Alvear formation (lower Pleistocene), Entre Ríos, Argentine. Ameghiniana, 42(4), 685-704. 